\title{
Bone Regeneration Based on Tissue Engineering Conceptions - A 21st Century Perspective
}

\author{
Jan Henkel ${ }^{1}$, Maria A. Woodruff ${ }^{1}$, Devakara R. Epari ${ }^{1}$, Roland Steck ${ }^{1}$, Vaida Glatt ${ }^{1}$, Ian C. Dickinson ${ }^{2}$, Peter \\ F.M. Choong 3,4,5, Michael A. Schuetz ${ }^{1,6}$, Dietmar W. Hutmacher ${ }^{1,7 *}$

\begin{abstract}
${ }^{1}$ Institute of Health \& Biomedical Innovation, Queensland University of Technology, Brisbane, Queensland, Australia; ${ }^{2}$ Orthopaedic Oncology Service, Princess Alexandra Hospital, Brisbane, Australia; ${ }^{3}$ Department of Surgery, University of Melbourne, St. Vincent's Hospital, Melbourne, Australia; ${ }^{4 D e p a r t m e n t ~ o f ~ O r t h o p a e d i c s, ~ S t . ~ V i n c e n t ' s ~ H o s p i t a l, ~ M e l b o u r n e, ~}$ Australia; 5Bone and Soft Tissue Sarcoma Service, Peter MacCallum Cancer Centre, Melbourne, Australia; ${ }^{6}$ Orthopaedic and Trauma Services, Princess Alexandra Hospital, Brisbane, Australia; 7George W Woodruff School of Mechanical Engineering, Georgia Institute of Technology, Atlanta, GA, USA
\end{abstract}

The role of Bone Tissue Engineering in the field of Regenerative Medicine has been the topic of substantial research over the past two decades. Technological advances have improved orthopaedic implants and surgical techniques for bone reconstruction. However, improvements in surgical techniques to reconstruct bone have been limited by the paucity of autologous materials available and donor site morbidity. Recent advances in the development of biomaterials have provided attractive alternatives to bone grafting expanding the surgical options for restoring the form and function of injured bone. Specifically, novel bioactive (second generation) biomaterials have been developed that are characterised by controlled action and reaction to the host tissue environment, whilst exhibiting controlled chemical breakdown and resorption with an ultimate replacement by regenerating tissue. Future generations of biomaterials (third generation) are designed to be not only osteoconductive but also osteoinductive, i.e. to stimulate regeneration of host tissues by combining tissue engineering and in situ tissue regeneration methods with a focus on novel applications. These techniques will lead to novel possibilities for tissue regeneration and repair. At present, tissue engineered constructs that may find future use as bone grafts for complex skeletal defects, whether from post-traumatic, degenerative, neoplastic or congenital/developmental "origin" require osseous reconstruction to ensure structural and functional integrity. Engineering functional bone using combinations of cells, scaffolds and bioactive factors is a promising strategy and a particular feature for future development in the area of hybrid materials which are able to exhibit suitable biomimetic and mechanical properties. This review will discuss the state of the art in this field and what we can expect from future generations of bone regeneration concepts.

Keywords: bone tissue engineering; regenerative medicine; additve manufacturing; clinical translation; scaffolds

Bone Research (2013) 3: 216-248. doi: 10.4248/BR201303002

\section{Introduction}

After 15 years of Tissue Engineering \& Regenerative Medicine 1.0 and another 10 years of 2.0 versions (1) the era of tissue engineering 3.0 has begun. This review will des-

*Correspondence: Dietmar W. Hutmacher

E-mail: dietmar.hutmacher@qut.edu.au

Received 11 J une 2013; Accepted 20 J uly 2013 cribe the state of the art of the bone tissue engineening field and present a perspective of its role in Tissue Engineering \& Regenerative Medic ine 3.0. Over the last ten years remarkable progress has been made in the development of surgical techniques for bone reconstruction. Although these sophistic ated techniques have transformed reconstructive surgery and significantly improved clinic al outcomes, they have already reached a number of their practic al limits to further improve health- 
care outcomes. Today major reconstructive surgenies (due to tra uma or tumour removal) a re still limited by the paucity of autologous materials available and donor site morbidity. Recent advances in the development of scaffold-based Tissue Engineering (TE) have given the surgeon new options for restoring form and function. There are now bioactive biomaterials (second generation) available that elicit a controlled action and reaction to the host tissue environment with a controlled chemical breakdown and resomtion to ultimately be replaced by regenerating tissue. Third-generation biomaterials are now being designed to stimulate regeneration of living tissuesusing tissue engineering and in situ tissue regeneration methods. Engineering functional bone using combinations of cells, scaffolds and bioactive factors are seen as a promising approach and these techniques will undoubtedly lead to ceaseless possibilities for tissue regeneration and repair. There are currently thousands of research papers and reviews available on bone tissue engineening, but there is still a major discrepancy between scientific research efforts on bone tissue engineering and the clinical application of such strategies. There is an evident lack of comprehensive reviews that cover both the scientific research aspect as well as the clinical translation and practical application of bone tissue engineering techniques. This review will therefore discuss the state of the art of scientific bone tissue engineering concepts and will also provide current approaches and future perspectives for the clinic al applic ation of bone tissue engineering.

\section{Bone biology}

Bone as an organ has next to its complex cellular composition a highly specialised organic-inorganic architecture which can be classified as micro- and nanocomposite tissue. Its mineralised matrix consists of 1) an organic phase (mainly collagen, 35\% dry weight) responsible for its rigid ity, visc oelastic ity and toughness; 2) a mineral phase of carbonated apatite ( $65 \%$ dry weight) for struc tural reinforcement, stiffness and mineral homeostasis; and 3) other non-collagenous proteins that form a mic roenvironment stimulatory to cellular functions (2). Bone tissue exhibits a distinct hierarchical structural organization of its constituents on numerous levels including macrostructure (cancellous and cortical bone), mic rostruc ture (Harversian systems, osteons, single trabeculae), sub-mic rostructure (lamellae), nanostructure (fibrillar collagen and embedded minerals) and subnanostructure (molecular structure of constituent elements, such as mineral, collagen, and non-collagenous organic proteins) (Figure 1) (3). Macroscopically, bone consists of a dense hard cylindrical shell of cortical bone along the shaft of the bone that becomes thinner with greater distance from the centre of the shaft towards the articular surfaces. Cortical bone encompasses increasing amounts of porous trabecular bone (also called cancellous or spongy bone) at the proximal and distal ends to optimise articular load transfer (2). In humans, trabecular bone has a porosity of $50-90 \%$ with an average trabecular spacing of around $1 \mathrm{~mm}$ and an average density of a pproximately $0.2 \mathrm{~g} \cdot \mathrm{cm}^{-3}(4-6)$. Cortical bone has a much denser structure with a porosity of $3-12 \%$ and an a verage density of $1.80 \mathrm{~g} \cdot \mathrm{cm}^{-3}(5,7)$.

On a microscopic scale, trabecular struts and dense cortical bone are composed of mineralized collagen fibres stacked parallel to form layers, called lamellae (3-7 $\mu \mathrm{m}$ thick) and then stacked in $a \pm 45^{\circ}$ manner (2). In mature bone these lamellae wrap in concentric layers (3-8 lamellae) around a central part named Haversian canal which containings nerve and blood vessels to form what is called an Osteon (or a Haversian system), a cylindrical structure running roughly parallel to the long axis of the bone (3). Cancellous bone consists of interconnecting framework of rod and plate shaped trabeculae. On a nanostructural level, the most prominent structures are the collagen fibres, surrounded and infiltrated by mineral. At the sub-nanostructural level three main materials are bone crystals, collagen molecules, and non-collagenous organic proteins. Forfurther details the reader is referred to (3).

Mineralised bone matrix is populated with four boneactive cells: osteoblasts, osteoclasts, osteocytes and bone lining cells. Additional cell types are contained within the bone marrow that fills the central intramedullary canal of the bone shaft and intertrabecular spaces near the articular surfaces (8). Bone has to be defined as an organ composed of different tissues and also senves as a mineral deposit affected and utilised by the body's endocrine system to regulate (among others) calcium and phosphate homeostasis in the circulating body fluids. Furthermore, recent studies indicate that bone exerts an endocrine function itself by producing homones that regulate phosphate and glucose homeostasis integrating the skeleton in the global mineral and nutrient homeostasis (9).

Bone is a highly dynamic form of connective tissue which undergoes continuous remodelling (the orchestrated removal of bone by osteoclasts followed by the formation of new bone by osteoblasts) to optima lly a dapt its structure to changing functional demands (mechanical loading, nutritional status etc.). From a material science point of view bone matrix is a composite material of a polymer-ceramic lamellar fibre-matrix and each of 
these design and material aspects influence the mechanical properties of the bone tissue (10). The mechanical properties depend on the bone composition (porosity, mineralisation etc.) as well as the structural organisation (trabecular or cortical bone architecture, collagen fibre orientation, fatigue damage etc.) (11). Collagen possesses a Young's modulus of 1-2 GPa and an ultimate tensile strength of 50-1000 MPa, compared to the mineral hydroxyapatite which has a Young's modulus of $\sim 130 \mathrm{GPa}$ and an ultimate tensile strength of $\sim 100 \mathrm{MPa}$. The resulting mechanical properties of the two types of bone tissue, namely the cortical bone and cancellous bone, are shown in Table 1 . Age and related changes in bone density have been reported to substantially influence the mechanical properties of cancellous bone (12). As outlined a bove, bone shows a distinct hierarchical structural organization and it is therefore important to also define the mechanical properties at mic rostructural levels (Table 2). Although the cancellous and cortical bone may be of the same kind of material, the maturation of the cortical bone material may alter the mechanical properties at the mic rostructural level.

Bone tissue is also known to be mechano-receptive; both nomal bone remodelling and fracture or defect healing are influenced by mechanical stimuli applied at the regenerating defect site and surrounding bone tissue (17-20). In contrast to most other organs in the human body, bone tissue is capable of true regeneration, i.e. healing without the formation of fibrotic scartissue (21). During the healing process basic steps of fetal bone development are recapitulated and bone regenerated in this way does not differ structurally or mechanic ally from the surrounding undamaged bone tissue (22). However, despite this tremendous regenerative capacity,

Table 1 Mechanical properties of compact (cortical) and spongy (cancellous) bone. Reproduced and modified from (13).

\begin{tabular}{lcc}
\hline Property & $\begin{array}{c}\text { Cortical } \\
\text { bone }\end{array}$ & $\begin{array}{l}\text { Cancellous } \\
\text { bone }\end{array}$ \\
\hline Compressive strength/MPa & $100-230$ & $2-12$ \\
Flexural, tensile strength/MPa & $50-150$ & $10-20$ \\
Strain to failure/\% & $1-3$ & $5-7$ \\
Fracture toughness/MPa m ${ }^{1 / 2}$ & $2-12$ & - \\
Young'smodulus/GPa & $7-30$ & $0.5-0.05$ \\
\hline
\end{tabular}

Table 2 Young's modulus (GPa) (according to various levels of architecture). Modified from (14-16) as listed in the table.

\begin{tabular}{ll}
\hline Arc hitecture & Young's modulus \\
\hline Wet specimen (mac rostructural) (14) & $14-20$ \\
Wet specimen (mic rostructural) (15) & 5.4 \\
Dry specimen (submic rostructure) (16) & 22 \\
\hline
\end{tabular}

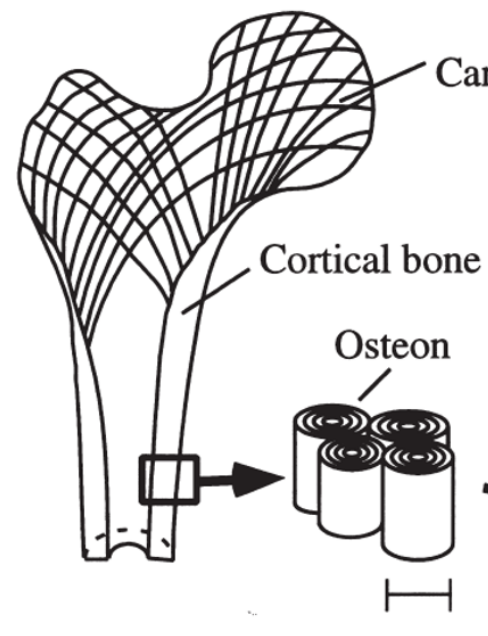

$10-500 \mu \mathrm{m}$
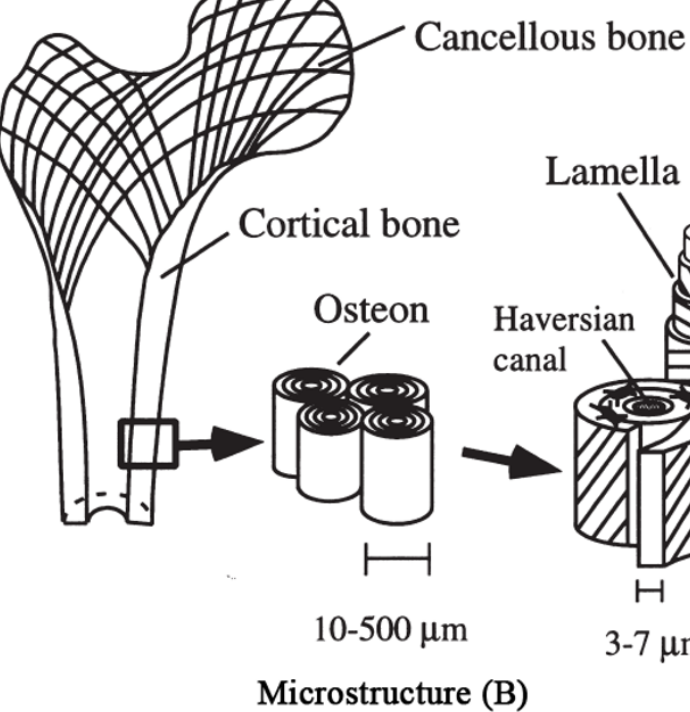

Microstructure (B)

Macrostructure (A)

Sub-microstructure (C)

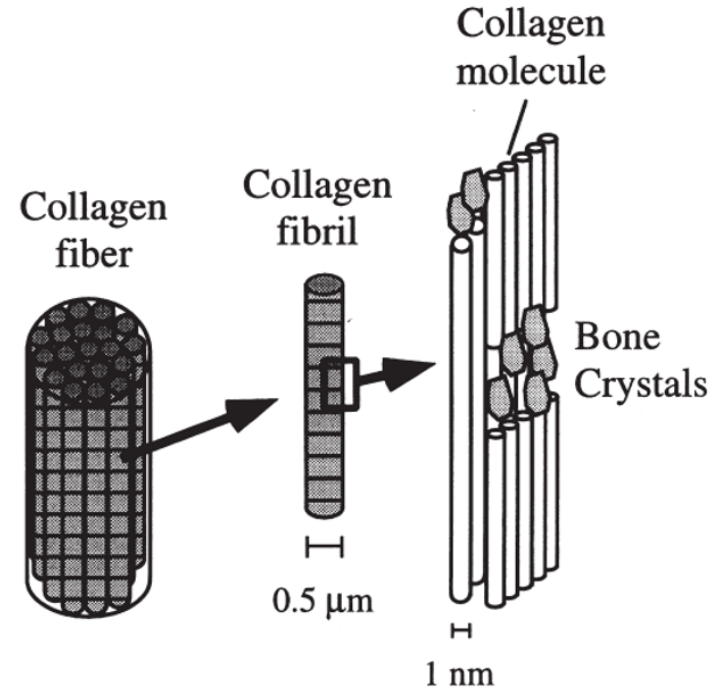

3-7 $\mu \mathrm{m}$

Nanostructure (D)

Figure 1 Hierarchical structural organization of bone: (A) cortical and cancellous bone; (B) osteons with Haversian systems; (C) lamellae; (D) collagen fibre assemblies of collagen fibrils; (E) bone mineral crystals, collagen molecules, and non-collagenous proteins. Reproduced with permission from (3), C1998 IPEM. 
$5-10 \%$ of all fractures are prone to delayed bony union or will progress towards a non-union and the development of a pseudarthrosis (23-24). Together with large traumatic bone defects and extensive loss of bone substance after tumour resection or revision surgery after failed arthroplasties, these pathological conditions still represent a major challenge in today's clinical practice. The range of bone graft materialsavailable to treat such problems in modem clinical practice essentially include autologous bone (from the same patient), allogeneic bone (from a donor), and demineralised bone matrices, as well as a wide range of synthetic bone substitute biomaterials such as metals, ceramics, polymers, and composite materials. During the last decades, tissue engineering strategies to restore clinical function have raised considerable scientific and commercial interest in the field of orthopaedic surgery as well as reconstructive and oromaxillofacial surgery. Yet, the trea tment of bone defects and the search for bone substitute materials is not just a modem day phenomenon, with its history reaching back through millennia.

\section{Bone grafting and bone substitutes in the last 4000 years}

The quest for the most efficient way to substitute for lost bone and to develop the best bone replacement material has been pursued by humans for thousands of years.

In Peru, archaeologists discovered the skull of a tribal chief from $2000 \mathrm{BC}$ in which a frontal bone defect (presumably from trepanation) had been covered with a $1 \mathrm{~mm}$-thick plate of hammered gold (25). Trephined Incan skulls have been found with plates made from shells, gourds, and silver or gold plates covering the defect areas (26). In a skull found in the ancient center of Ishtkunui (Amenia) from approx. 2000 BC, a $7 \mathrm{~mm}$ diameter skull defect had been bridged with a piece of a nimal bone (27). These pursuits are not limited to skull surgeries involving bone substitutes. Ancient Egyptians have been shown to have profound knowledge of orthopaedic und traumatological procedures with Surgeons having implanted iron prostheses for knee joint replacement as early as $600 \mathrm{BC}$, as analyses of preserved human mummies have revealed (28).

The first modem era report of a bone xenograft procedure is believed to be the Dutch surgeon Job Janszoon van Meekeren in 1668 (29-30). A skull defect of a Russian nobleman was successfully treated with a bone xenograft taken from the calvaria of a deceased dog. The xenograft was reported to have become fully incorporated into the skull of the patient. In the 1800s, plaster of Paris (Calcium sulphate) was used to fill bone cavities in patients suffering from Tuberculosis (31). Attempts were also made to fill bone defects with cylinders made from ivory (32). In 1820 the Geman surgeon Phillips von Wa Iters desc ribed the first c linic al use of a bone autograft to reconstruct skull defects in patients after trepanation (33). Walters suc cessfully repaired trepanation holes, following surgery to relieve intracranial pressure, with pieces of bone taken from the patient's own head. In 1881, Scottish surgeon William MacEwen described the first allogenic bone grafting procedure: He used tibial bone wedges from three donors that had undergone surgery for skeletal deformity correction (caused by rickets) to reconstruct an infected humerus in a 3-year-old child (34)

Major contributions leading to the development of modem day bone grafting procedures and bone substitutes have been made by Ollier and Barth in the late 1800s. Louis Léopold Ollier camied out extensive experiments to study the osteogenic properties of the periosteum and other various approaches to new bone formation, mainly in rabbit and dog models. He also meticulously reviewed the literature on bone regeneration available at that time and in 1867 he published his 1000-page textbook 'Traite experimentel et clinique de la regeneration des os et de la production artific ielle du tissu osseux', in which he described the term 'bone graft' ("greffe osseuse") for the first time (35). In 1895 the German surgeon Arthur Barth published his treatise 'Ueber histologische Befunde nach Knochenimplantationen' ('On histological findings after bone implantations') presenting his results of various bone grafting procedures involving the skull and long bones (humenus, foream bones) of dogs and rabbits including histological assessment (36). Today, both Ollier's and Barth's work are considered to be milestones in the development of present day bone grafting procedures and bone substitute materials.

With the development of new orthopaedic techniques and increased numbers of joint replacement procedures (prostheses), the demand for bone grafts increased in the $20^{\text {th }}$ century, leading to the opening of the first bone bank for allogenic bone grafts in New York in 1945 (37). But the risk of an immunological reaction from transplanted allogenic bone material was soon recognized and addressed in various studies (38-39). Several procedures such as the use of hydrogen peroxide to macerate bone grafts ("Kieler Span") in the 1950s and 1960s to overcome antigenity were not successful (40-41). Today, bone substitute materials such as (bovine) bone chips are routinely used in clinical practice after being pretreated to remove antigen structures. However, due to 
the processing steps necessary to abolish antigenicity, most of these grafts do not conta in viable cells or growth factors and are therefore inferior to viable autologous bone graft options. When allografts with living cells are transplanted, there is a risk of transmitting viral and bacterial infections: Transmission of human immunodefic iency virus (HIV), hepatitis C virus (HCV), human T-lymphozytic virus (HTLV), unspecified hepatitis, tuberculosis and other bacteria has been documented (mainly) for allografts (mainly from those containing viable cells) (42).

As early as 1932, the work of the Swiss H. Matti proved the paramount meaning of autologous cancellous bone grafts for bone regeneration approaches (43). Having conducted various experiments on the osteogenic potential of autologous and allogenic bone, Schweiberer concluded in 1970 that the autologous transplant remains the only really reliable transplantation material of the future, if applied to bring about new bone formation or crucially to support the bridging bone defects (44). Even though this statement was made more than 50 yearsago, it still remains valid today, when bone is still the second most transplanted material, second only to blood. Worldwide more than 3.5 million bone grafts (either autografts or allografts) are performed each year (45). Recent advances in technology and surgical pro-cedures have signific antly increased the options for bone grafting material, with novel products designed to replace both the structural properties of bone, as well as promote faster integration and healing. The number of procedures requining bone substitutes is increasing, and will continue to do so as the population ages and physical activity of the elderly population increases. Therefore, while the current bone grafting market globally is estimated to be in excess of $\$ 2.5$ billion US each year, it is expected to increase at a compound annual growth rate of $7-8 \%(45)$

Although the last decades have seen numerous innovations in bone substitute materials, the treatment of bone defects with autologous bone grafting material is still considered to be the 'Gold Standard' against which all other methods are compared (46). Autologous bone combines all the properties desired in a bone grafting material: It provides a scaffold for the ingrowth of cells necessary for bone regeneration (=osteoconductive); it promotes the proliferation of stem cells and their differentiation into osteogenic cells (=osteoinductive) and it holds viable cells that can form new bone tissue (=osteogenic) $(22,47)$. However, the available volume of autologous bone graft from a patient is limited and an additional surgical procedure is required to harvest the grafting material which is associated with a significant risk of donor site morbidity. $20-30 \%$ of autograft patients experience morbidity such as chronic pain or dysa esthesia at the graft-harvesting site (48). Large bone defects $(>5 \mathrm{~cm})$ may be treated with bone segment transport or free vascularized bone transfer (49), as the use of an autologous bone graft alone is not recommended because of the risk of graft resorption despite good soft tissue coverage (50). The vasculanised fibula autograft (51) and the llizarov method (52-54) are the most commonly used treatment methods for larger bone defects; however, complications are common and the process can be laborious and painful for the patient as she/he may be required to use extemal fixation systems for up to one and half years $(49,55-56)$.

The limitations of existing bone grafting procedures, either autologous or allogenic in nature, and the increased demand for bone grafts in limb salvage surgeries for bone tumours and in revision surgeries of failed arthroplasties have renewed the interest in bone substitute materials and altemative bone grafting procedures (57). In 1986, Masquelet and colleagues (58) first described a new two-stage technique taking advantage of the body's immune response to foreign materials for bone reconstruction. The authors called it the 'concept of induced membranes' - soon to become known as the 'Masquelet technique': In a first step, a radical debridement of necrotic bone and soft tissue is followed by the filling of the defect site with a polymethylmethacrylate (PMMA) spacer and stabilisation with an extemal fixator. After the definitive healing of the soft tissue, a second procedure is performed 6-8 weeks later, when the PMMA spacer is removed and a morcellised cancellous bone graft (from the iliac crest) is inserted into the cavitiy (59-60). The cement spacer was initially thought to prevent the collapse of the soft tissue into the bone defect and to prepare the space forbone reconstruction. However, it was soon discovered that the PMMA spacer does not only serve as a place holder, but that a foreign body reaction to the spaceralso induces the formation of a membrane that possesses highly desirable properties for bone regeneration (60-61): The induced membrane was shown to be richly vascularised in all layers; the inner membrane layer (facing the cement) composed of synovial like epithelium and the out part is made from fibroblasts, myoblasts and collagen. The induced membrane has also been shown to secrete various growth factors in a time-dependent manner: High concentrations of vascular endothelial growth factor (VEGF) as well as transforming growth factor $\beta$ (TGF $\beta$ ) are secreted as early as the second week after implantation of the PMMA spacer, bone morphogenetic protein 2 (BMP-2) concentration peaks at the fourth week. The induced membrane stimulates the prolifera- 
tion of bone marrow cells and differentiation towardsan osteoblastic lineage. Finally, clinical experience has shown that the cancellous bone inside the induced membrane is not subject to resontion by the body. Ever since its introduction the 'induced membrane'-technique has been used very successfully in various c linic al cases (see (59) and references therein). However, the Mas quelet technique still requires the harvesting of an autologous bone graft, and with that come all the potential aforementioned complications. Furthemore, the use of altemate bone substitute materials, such as hydroxyapatite tricalcium phosphate, in combination with the Masquelet technique has so far yielded results inferior to the use the Masquelet technique with autologous bone grafting material $(59,62)$.

Besides the Masquelet technique, a more recent innovation has also significantly improved the clinical approach to restoring bone defects. The development of the Reamer-Irigator-Aspirator (RIA ${ }^{\odot}$ )-System (DePuySynthes) has given clinicians an altemative to iliac crest harvesting to retrieve bone grafting materials from patients: The RIA System provides imigation and aspiration during intramedullay reaming, a llowing the harvesting of finely morselised autologous bone and bone marrow for surgical procedures requiring bone grafting material (63). The RIA was initially developed to lower the intramedullary pressure during the reaming of long bones to reduce the risk of fat embolisms and pulmonary complications such as the Acute Respiratory Distress Syndrom (ARDS), as well as to reduce local themal necrosis of bone tissue (64-65). However, the finely morselised a utologous bone and bone marrow that is collected by the RIA has been shown to be rich in stem cells, osteogenic cells and growth factors and has been recognized to be a suitable bone graft altemative to the iliac crest autograft tissue (66-67). Also, RIA enables the harvesting of larger bone graft volumes compared to the iliac crest (approx. $40 \mathrm{~cm}^{3}$ for the femur and $33 \mathrm{~cm}^{3}$ for the tibia) $(48,65)$. Furthermore, the risk of complic ations from the harvesting procedure has been reduced significantly (RIA 6\% vs. $19.37 \%$ for iliac crest autografts) (68). Since its introduction, the indications for use of RIA have been further extended to include the treatment of postoperative osteomyelitis (69) and the harvesting of mesenchymal stem cells (MSCs) (70). The innovation driven by the RIA systems was so signific ant, that the J oumal "Injury" has dedicated a complete issue to the data available on RIA and its applications recently (71). A systematic review on the Reamer-imigator-aspirator indic ations and clinical results has recently been published by Cox et al (72). The Masquelet technique as well as the RIA-system is nowadays frequently used in clinical practice, in- dependently. However, the two techniques may also be combined to further improve their effectiveness when treating severe bone defects, for example in posttraumatic limb reconstruction (73). An example of a case from one of our author's clinical practice (M.S.) combining the use of Masquelet technique and the use of the RIA-system to treat a complex case of tibial nonunion is provided in Figure 2.

Both the Masquelet technique and the development of the RIA-system represent significant improvements in today's clinical approach to bone reconstruction and regeneration. However, utilising these techniques, we have still not been able to replace autologous bone grafting in order to avoid surgical graft retrieval procedures with all the associated disadvantages. However with research looking towards inc reasing ly sophistic ated bone tissue engineering techniques and their first clinical applications, the quest for developing improved bone substitute material advances to the next level.

\section{Bone substitute materials (BSM)}

Bone substitutes can be defined as "a synthetic, inorganic or biologically organic combination-biomaterialwhich can be inserted for the treatment of a bone defect instead of autogenous or allogenous bone" (74). This definition applies to numerous substances and a variety of materials have been used over time in an attempt to substitute bone tissue. Although merely of historic interest and with no significance in modem therapies, the use of seashells, nuts, gourds and so forth show that humans have strived for BSM for thousands of years.

With the introduction of tissue engineering and its clinical application the regenerative medicine in 1993 (75) the modem day quest for BSMs has undergone a significant change. The limitations of current clinical approaches have necessitated the development of altema tive bone repair techniques and have driven the development of scaffold-based tissue engineening strategies. In the past, mostly inert bone substitute materials have been used, functioning mainly as space holders during the healing processes. Now a paradigm shift has taken place towards the use of new 'intelligent' tissue engineering biomaterials that would support and even promote tissue re-growth (76).

According to the "diamond concept" of bone tissue engineering (77-78), an ideal bone substitute material should offer an osteoinductive three-dimensional structure, contain osteogenic cells and osteoinductive factors, have sufficient mechanical properties and promote vascularisation. Despite extensive research in the field of bone tissue engineering, apart from the "gold standard"

www.boneresearch.org | Bone Research 

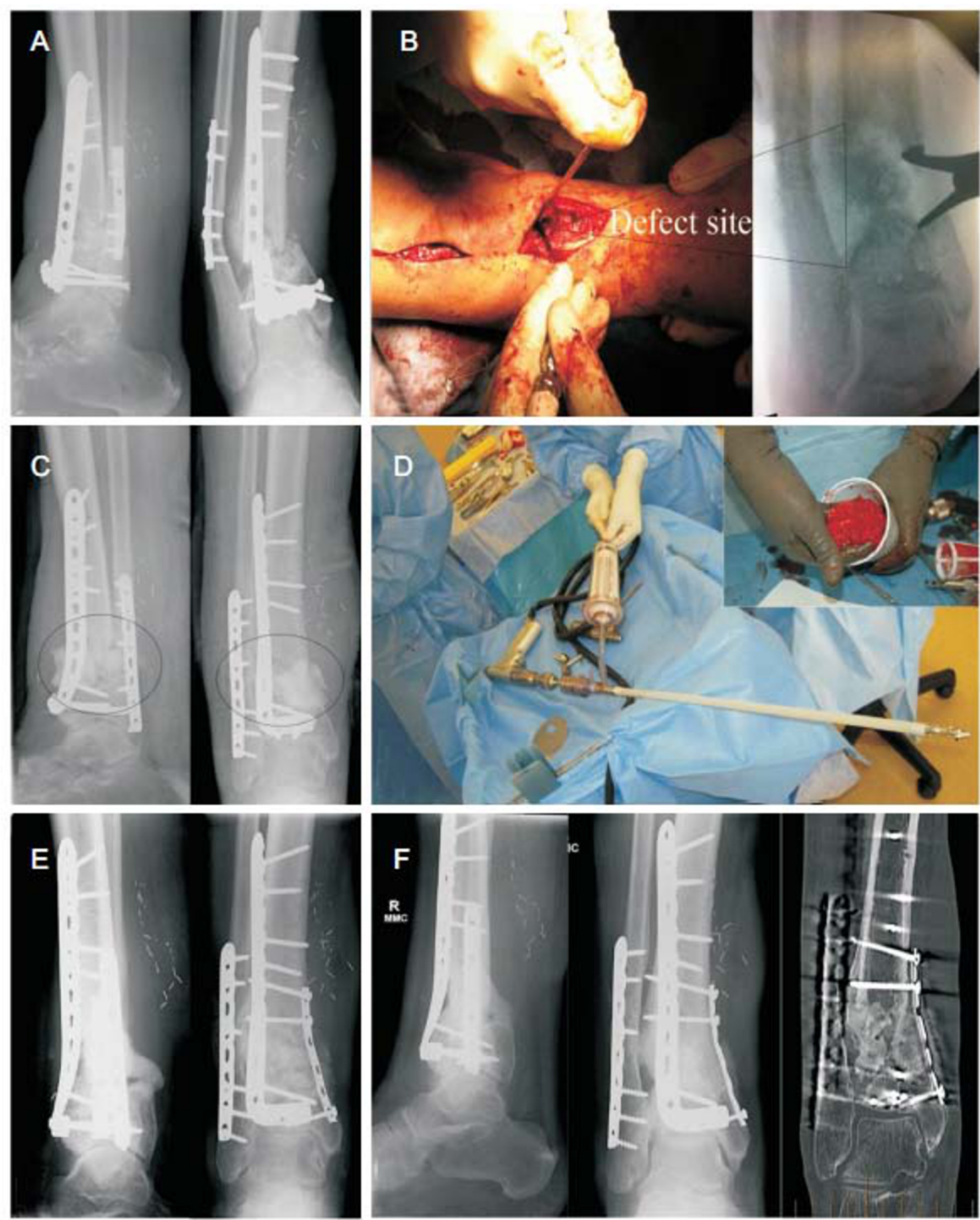

Figure 2 Clinical case combining the Masquelet-technique and the RIA-system to treat a tibial non-union. 51 year old male acquired a Gustillo 3B fracture of the right tibia and fibula and was treated with a stage procedure with locked plating and a free flap. The patient's progress was very slow and an implant failure occurred 8 months post-operatively (A). The patient was then referred for the further management and underwent debridement of the non-union site on the distal tibia by lifting the flap (B). The size of the extensive bone defect is shown in B (intraoperative image of situs and X-ray image with retractor in defect site). Additionally, a PMMA bone cement spacer was inserted into the tibial defect as part of the Masquelet technique. Postop X-ray images after surgery with the PMMA spacer (circles) in place (C). 8 weeks later the PMMA spacer was removed and the induced membrane at the defect site was packed with autologous cancellous bone graft obtained from the femur using the Reamer-Irrigator-Aspirator (RIA) technique. (D) shows assembled RIA system, insert showing morselised autologous bone and bone marrow graft obtained. Postop films after the second surgery (E). 7 weeks after bone grafting the defect showed good healing and patient was able to fully bear weight as tolerated. Over the following 2 months X-ray images showed progressive bridging of the zone and he was able to return to work with light duties. He was reviewed again 7 months post-surgery and had returned to work full-time and was walking long distances without any support (F). 
autograft bone, no currently available BSM can offer these properties in one single material. Therefore, the fundamental concept underlying tissue engineering is to combine a scaffold or three-dimensional construct with living cells, and/or biologically active molecules to form a "tissue engineening construct" (TEC), which promotes the repair and/or regeneration of tissues (79-80).

Currently used BSM can be classified into different subgroups according to their origin $(76,81)$ :

1) BSM of natural origin

This group consists of harvested a utogenous bone grafts as well as allogenic BSM, such demineralised bone matrix, cortic oc a nc ellous or cortic al grafts, cancellous chips (from either cadavers or living donors) (82-84). Xenogenic materials, for example porous natural bone hydroxyapatite from animal bones (bovine, equine, porcine etc.) are also part of this group (85). Phytogenic materials such as bone-analogue calcium phosphate originally obtained from marine algae or coral derived materials, also fall into this category (86-87).

2) Synthetic (alloplastic) materials

This groups contains ceramic s such as bioactive glasses (88), Tric a lc iumphosphates (TCP) (89-90), Hydroxya patite (HA) (91-93) and glass ionomer cements as well as Calcium Phosphate (CP) ceramics (94). Metals such as tita nium also belong to this group. Furthermore polymers including polymethylmethacrylate (PMMA), polylactides/ poliglycolides and copolymers as well as polycaprolactone (PCL) (95) are summarised in this group (76, 79, 96-97).

3) Composite materia ls

BSM combining different materia ls such as ceramic sand polymers are referred to as composite materials (92, 98-99). By merging materials with different structural and biochemical properties into composite materials, the properties of composite materials can be modified to achieve more favourable characteristics, for instance with respect to biodegradability $(79,97)$.

4) BSM combined with growth factors

Natural or recombinant growth factors such a bone morphogenic protein (BMP), platelet-derived growth factor (PDGF), tranforming growth factor- $\beta$ (TGF- $\beta$ ), insulin-like growth-factor 1 , vascular end othelial growth factor (VEGF) and fibroblast growth factor can be added to increase the biological activity of BSM (100-101). For example, a composite material made of medicalgrade polycaprolactone-tricalcium phosphate (mPCLTCP) scaffolds (combined with recombinant human BMP-7) has been demonstrated to completely bridge a c ritic al-sized $(3 \mathrm{~cm})$ tibial defect in a sheep model (102). 5) BSM with living cells Mesenchymal stem cells (103-105), bone marrow stromal cells (106-107), periosteal cells (108-109), osteoblasts (110) and embryonic (111) as well as adult stem cells (112) have been used in bone tissue engineering $(22,101$, 113-116). These cells can generate new tissue alone or can be used in combination with scaffold matrices.

BSMscan also be classified according to their properties of action. An overview of the currently a vailable BSM for clinical (orthopaedic) use and their mode of action is given in Table 3 (reproduced from (117))

\section{Three-dimensional scaffolds in bone tissue engineering}

Scaffolds serve as three-dimensional structures to guide cell migration, proliferation and differentiation. In load bearing tissues, it also serves as temporary mechanical support structure. Scaffolds substitute for the function of the extracellular matrix and need to fulfil highly specific criteria. An ideal scaffold should be (i) three-dimensional and highly porous with an interconnected pore network for cell growth and flow transport of nutrients and metabolic waste; (ii) should have surface properties which are optimized for the attachment, migration, proliferation and differentiation of cell types of interest (depending on the targeted tissue); (iii) be biocompatible, not elicit an immune response and be biodegradable with a controllable degradation rate to compliment cell/tissue in-growth and maturation; (iv) its mechanical properties should match those of the tissue at the site of implantation and (v) the scaffold structure should be easily and efficiently reproducible in various shapes and sizes (97).

\section{Biocompatibility}

Biocompatibility represents the ability of a material to perform with an appropriate response in a specific application (118). As a general rule, scaffolds should be fabricated from materials that do not have the potential to elicit immunological or clinically detectable primary or secondary foreign body reactions (119). Parallel to the formation of new tissue in vivo, the scaffold may undergo degradation via the release of by-products that are either biocompatible without proof of elimination from the body (biodegradable scaffolds) orcan be eliminated through natural pathways from the body, either by simple filtration of by-products or after their metabolisation (bioresorbable scaffolds) (97). Due to poor vascularisation or low metabolic activity, the capacity of the surrounding tissue to eliminate the by-products may be low leading to a build up of the by-products thereby causing local temporary disturbances (97): A massive in vivo release of acidic degradation by-products leading to inflammatory reactions has been reported for several 
Bone tissue engineering

Table 3 Bone grafts and graft substitutes currently used in clinical orthopaedic applications. Reproduced with permission from (117), (c) Dr Samit Kumar Nandi, 2010.

\begin{tabular}{|c|c|c|c|}
\hline Class & Description & Examples & Properties of action \\
\hline Autograft based & Used alone & & $\begin{array}{l}\text { Osteoc onductive, Osteoinductive, } \\
\text { Osteogenic }\end{array}$ \\
\hline Allograft based & $\begin{array}{l}\text { Allograft bone used alone or in combination } \\
\text { with other materials }\end{array}$ & $\begin{array}{l}\text { Allegro, Orthoblast, } \\
\text { Grafton }\end{array}$ & Osteoconductive, Osteoinduc tive \\
\hline Factorbased & $\begin{array}{l}\text { Natural and recombinant growth factors } \\
\text { used alone or in combination with other } \\
\text { materials }\end{array}$ & TGF- $\beta$, PDGF, FGF, BMP & $\begin{array}{l}\text { Osteoinductive, Both osteoconduc tive } \\
\text { and osteoinductive with camier } \\
\text { materials }\end{array}$ \\
\hline Cell based & $\begin{array}{l}\text { Cellsused to generate new tissue alone or } \\
\text { seeded onto a support matrix }\end{array}$ & Mesenchymal stem cells & $\begin{array}{l}\text { Osteogenic } \\
\text { Both osteogenic and osteo- conductive } \\
\text { with camer materials }\end{array}$ \\
\hline Ceramic based & $\begin{array}{l}\text { Includescalcium phosphate, calcium sulfate, } \\
\text { and bioactive glass used alone or in } \\
\text { combination }\end{array}$ & $\begin{array}{l}\text { Osteograf, Osteoset, } \\
\text { Nova Bone }\end{array}$ & $\begin{array}{l}\text { Osteoconductive } \\
\text { Limited osteoinductive when mixed } \\
\text { with bone ma row }\end{array}$ \\
\hline Polymerbased & $\begin{array}{l}\text { Includes degradable and nondegra- dable } \\
\text { polymers used alone and in combination } \\
\text { with other materials }\end{array}$ & Cortoss, OPLA, Immix & $\begin{array}{l}\text { Osteoconductive } \\
\text { Bioresorbable in degradable polymer }\end{array}$ \\
\hline Miscellaneous & Coral HA granules, blocks and composite & ProOsteon & $\begin{array}{l}\text { Osteoconductive } \\
\text { Bioresorbable }\end{array}$ \\
\hline
\end{tabular}

bioresorbable devices made from polylactides (120-122). Another example is the increase of osmotic pressure or pH caused by local fluid accumulation or transient sinus formation from fibre reinforced polyglycolide pins used in orthopaedic applications (120). It is also known that calcium phosphate biomaterial particles can cause inflammatory reactions after being implanted (although this inflammatory reaction may be considered desirable to a certain extent as it subsequently stimulates osteoprogenitor cell differentiation and bone matrix deposition) (123). These examples illustrate that potential problems related to biocompatibility in tissue engineening constructs for bone and cartilage applications may be related to the use of biodegradable, erodible and bioresorbable polymer scaffolds. Therefore, it is important that the three dimensional Tissue Engineening Construct (TEC) is exposed at all times to sufficient quantities of neutral culture media when undertaking cell culture procedures, especially during the period where the mass loss of the polymer matrix occurs (97). For applications in vivo, it is of course not possible to expose the TEC to neutral media, and one therefore has to carefully take into account the local specifications ( $\mathrm{pH}$, vasculanisation, metabolic activity etc) of the tissue to be engineered when accessing biocompatibility of a TEC.

Mechanical properties and degradation kinetics

The design of tissue engineering scaffolds needs to consider physico-chemic al properties, morphology and bio- mechanical properties as well as degradation kinetics. The scaffold structure is expected to guide the development of new bone formation by promoting attachment, migration, proliferation and differentiation of bone cells. Parallel to tissue formation, the scaffold should also undergo degradation in order to allow for ultimate replacement of scaffold material with newly formed, tissue engineered bone. Furthermore, the scaffold is also responsible for (temporal) mechanical support and stability at the tissue engineering site until the new bone is fully matured and is able to withstand mechanical load. As a general rule, the scaffold material should be sufficiently robust to resist changes in shape resulting from the introduction of cells into the scaffold (each of which should capable of exerting tractional forces) and from wound contraction forces that would be evoked during tissue healing in vivo (79). In order to achieve optimal results, it is therefore necessary to carefully balance the biomechanical properties of a scaffold with its degradation kinetics. A scaffold material has to be chosen that degrades and resorbs at a controlled rate, giving the TEC suffic ient mechanic al stability at all times, but at the same time allowing new in vivo formed bone tissue to substitute for its structure. Figure 3 depicts the interdependence of molecular weight loss and mass loss of a slow degrading composite scaffold and also shows the corresponding stages of tissue regeneration (80).

At the time of implantation the biomechanical properties of a scaffold should match the structural pro- 
perties of the tissue it is implanted into as closely a spossible (124). It should possess suffic ient structural integnity for the period until the engineered tissue ingrowth has replaced the slowly disappearing scaffold matrix with regards to mechanical properties. In bone tissue engineering the degradation and resorption kinetics of the scaffold have to be controlled in such a way that the bioresorbable scaffold retains its physical properties for at least 6 months to enable cell and tissue remodelling to achieve stable biomechanical conditions and vascularisation at the defect site (97). Apart from host a natomy and physiology, the type of tissue that is a imed to be engineered also has a profound influence on the degree of remodelling: in cancellous bone the remodelling takes 3-6 months, while cortical bone will take twice as long, approximately 6-12 months, to remodel (79). Whether the TEC will be part of a load bearing or non-load bearing site will also significantly influence the needsfor mechanic al stability of the TEC as mechanical loading can directly affect the degradation behaviour as well (79). Utilising orthopaedic implants to temporarily stabilise the defect area also influences the requirements for biomechanical stability of the TEC significantly (18, 125). It is therefore crucial to meticulously select the scaffold material individually for each tissue engineening approach to tailor the mechanical properties and degradation kinetics exactly to the purpose of the specific TEC (97). Consequently, there is not one "ideal scaffold material" for all bone tissue engineering purposes, but the choice depends on the size, type and location of the bone tissue to be regenerated.

\section{Surface Properties}

The surface area of a scaffold represents the space where pivotal interactions between biomaterial and host tissue take place. The performance of a TEC depends fundamentally on the interaction between biological fluids and the surface of the TEC, and it is often mediated by proteins absorbed from the biological fluid (126). The initial events include the orientated adsorption of molecules from the surrounding fluid, creating a specific interface to which the cells and other factors respond to the macrostructure of the scaffold as well as the microtopography and chemical properties of the surface determine which molecules are adsorbed and how cells will attach and align themselves (127). The focal attachments ma de by the cells with their substrate then determines cell shape, which in tum transduces signals via the cytoskeleton to the nucleus resulting in expression of specific proteins which may be structural or signal-related and contribute towards the cell phenotype.
Due to technical progress, we are now able to manipulate materials at the atomic, molecular, and supramolecular level, and bulk materials and surfaces can be designed at a similar dimension to that of the nanometer constituent components of bone (2): In natural bone, hydroxya patite plates a re approximately between $25 \mathrm{~nm}$ in width and $35 \mathrm{~nm}$ in length while collagen type 1 is a triple helix $300 \mathrm{~nm}$ in length, $0.5 \mathrm{~nm}$ in width and with a periodicity of $67 \mathrm{~nm}$ (128). "Nanomaterials" commonly refers to materials with basic structural units in the range 1-100 nm (nanostructured), crystalline solids with grain sizes between 1 and $100 \mathrm{~nm}$ (nanocrystals), individual layers or multilayer surface coatings in the range 1-100 nm (nanocoatings), extremely fine powders with an average particle size in the range $1-100 \mathrm{~nm}$ and fibres with a diameter in the range $1-100 \mathrm{~nm}$ (nanofibres) (2). The close proximity of the scale of these materials to the scale of natural bone composites makes the application of nanoma terials for bone tissue engineering a very promising strategy. Surfaces with nanometer topography can promote the availability of amino acid and proteins for cell adhesion to a great extent, for example, the adsorption of fibronectin and vitronectin [two proteins known to enhance osteoblast and bone foming cell function (129)] can be significantly increased by decreasing the grain size on the scaffold/implant surface below $100 \mathrm{~nm}$ (130). It has also been shown that cal cium-mediated cell protein adsorption on nanophase material promotes unfold ing of these proteins promoting bone cell adhesion and function (130). Current literature supports the hypothesis that by creating surface topographies with characteristics that approximate the size of proteins, a certain control over protein adsorption and interactions will be possible. Since the surface characteristics regarding roughness, topography and surface chemistry are then transcribed via the protein layer into information that is comprehensible for the cells (127), this will enable the fabrication of surface properties direc tly targeted at binding spec ific cell types. In vitro, osteoblast adhesion, proliferation and differentiation and calcium deposition is enhanced on nanomaterials with grain sizes less than $100 \mathrm{~nm}$ (130-131). The adherence of osteoblasts has been shown to increase up to threefold when the surface is covered with nanophase titanium particles instead of conventional titanium particles (132). Nano- and microporosiy has also been shown to promote osteogenic differentiation (133) and osteogenesis (134). The use of nanomaterials to achieve better osteointegration of orthopaedic implants and for bone tissue engineering approaches has been extensively summarised in several recent reviews $(2,135-138)$ and will not be reviewed in its entirety here. 


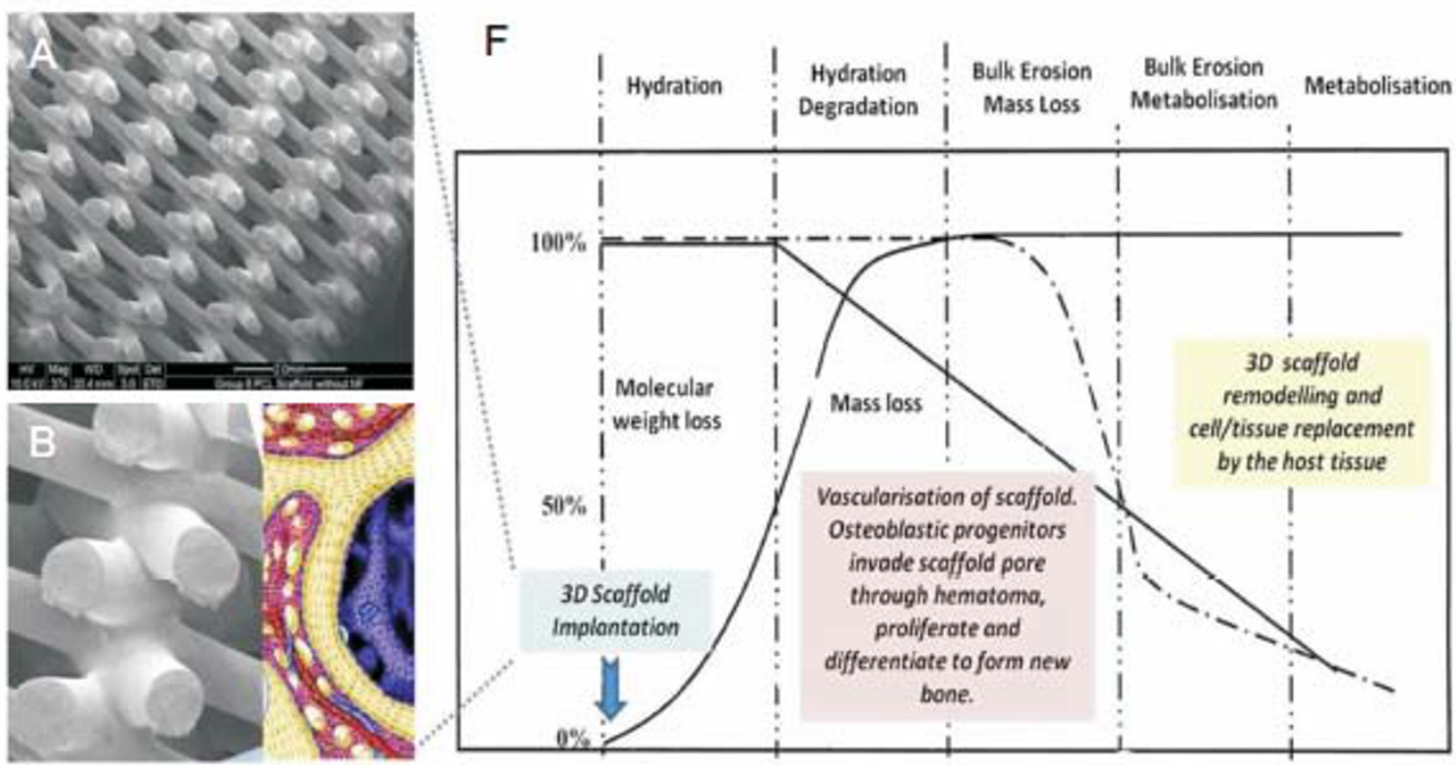

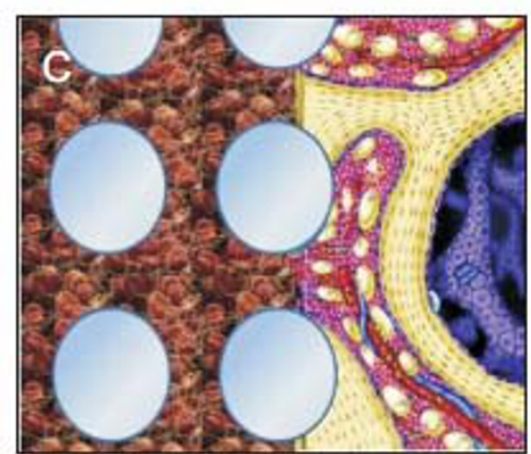

-0 -

Hematoma forms around the scaffold within hours of scoffold implantation

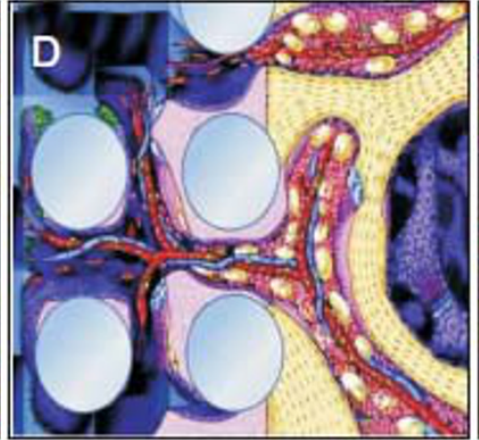

-1- Time (months)

After several weeks the scaffold become vascularised

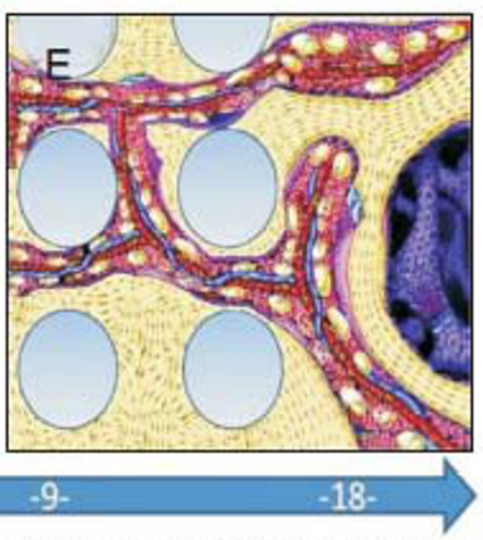

After several months new bone forms around the scaffold struts with characteristic osteon formation and vascularity

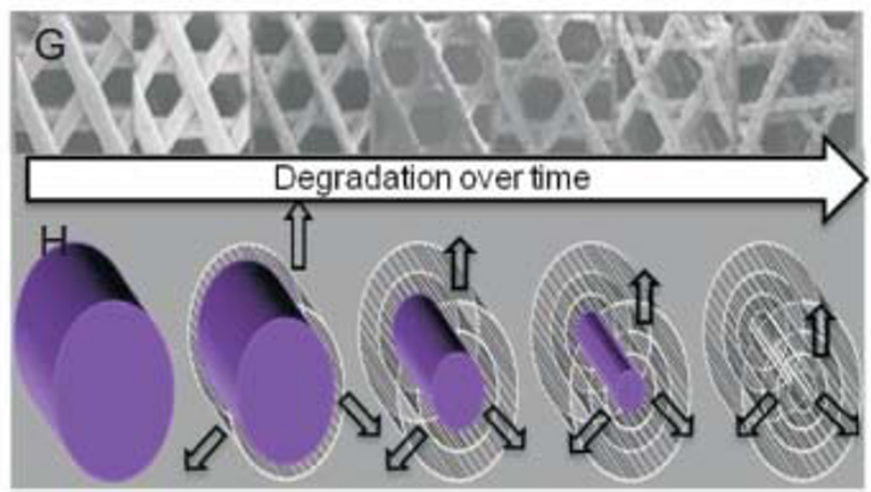

Figure 3 Schematic illustrating the interdependence of molecular weight loss and mass loss of a slow-degrading composite scaffold plotted against time, which corresponds with tissue regeneration. Scaffold, as shown by SEM (A) is implanted at $t=0$ (B) with lower figures (C-E) showing a conceptual illustration of the biological processes of bone formation over time. The scaffold is immediate filled with a hematoma on implantation (C) followed by vascularization (D) and gradually new bone is formed within the scaffold (E). As the scaffold degrades over time there is increased bone remodeling within the implant site until eventually the scaffold pores are entirely filled with functional bone and vascularity. SEM of scaffold degraded over time $(G)$ with associated schematic visualization of how mPCL-TCP scaffolds degrade via long-term bioerosion process, which takes up to 36 months in vivo (h). Reproduced with permission from (80), () Elsevier Ltd 2012. 
However, it becomes clear that rough scaffold surfaces favour attachment, proliferation and differentiation of anchorage-dependent bone forming cells (139). Osteogenic cells migrate to the scaffold surface through a fibrin clot initially established immediately after implantation of the TEC from the haematoma caused by the surgic al procedure (101). The migration causes retraction of the temporary fibrin matrix and, if not well secured, can lead to detachment of the fibrin from the scaffold during wound contraction leading to decreased migration of the osteogenic cells into the scaffold (140-141).

With regards to surface chemistry, degradation propertiesand by-products (relating to $\mathrm{pH}$, osmotic pressure, inflammatory reactions etc.) are of importance and have been briefly discussed already. In the following section, the role of calcium phosphate in the osteoinductivity of biomaterials will be summarized as an example of how surface chemistry may be manipulated to benefit scaffold properties. To date, most synthetic biomaterials that have been shown to be osteoinductive contained calcium phosphate underlining the crucial role of calcium and phosphate in osteoinduction properties of biomaterials (142). As summarised above, adequate porosity and pore size is crucial for bone tissue engineering scaffolds in order to allow sufficient vascularisation and enable a supply of body fluids throughout the TEC. Together with this nutrient supply, a release of calcium and phosphate ions from the biomaterial surface takes places and is believed to be the origin of bioactivity of calc ium phosphate biomaterials (143-145). This process is followed by the precipitation of a biological carbonated apatite layer (that contains calcium-, phosphate- and other ions such as magnesium as well as proteins and other organic compounds) that occurs when the concentration of calcium and phosphate ions has reached super saturation level in the vicinity of the implant (142, 146-147). This bone-like biological carbonated apatite layer is thought to be physiological triggerfor stem cells to differentiate down the osteogenic lineage or could induce the release of growth factors that complement this process (142). For biomaterials lacking calcium phosphate particles, the roughness of the surface is considered to act as a collection of nucleation sites for calcium phosphate precipitation from the hosts' body fluids, thereby forming a carbonated apatite layer.

Companing calcium phosphate $(\mathrm{CaP})$ coated fibrous scaffolds (fibre diameter approx $50 \mu \mathrm{m}$ ) made from medical grade polycaprolactone ( $\mathrm{MPCL}$ ) with non-coated $\mathrm{mPCL}$-scaffolds, we have shown that CaP-coating is beneficial for new bone formation in vitro, enhancing alkaline phosphatase activity and mineralisation within the scaffolds (148). Interestingly, other research has shown that the implantation of highly soluble carbonated apatite ceramics alone did not result in bone induction in vivo (149), suggesting that a relatively stable surface (e.g. through a composite material that contains a less soluble phase) is needed for the facilitation of bone formation as discussed above (see "mechanical properties and degradation kinetics"). Bone formation requires a stable biomaterial interface and therefore, too rapid in vivo dissolution of calcium phosphate materials has been shown to be unfavourable for the formation of new bone tissue (150-151). Chai et al. and Barradas et al. have recently reviewed the effects of calcium phosphate osteogenicity in bone tissue engineering $(150,152)$.

Further comprehensive reviews on the influence of surface topography and surface chemistry on cell attachment and proliferation for orthopaedic implants and bone tissue engineering are available $(2,126,142,150$ 153).

\section{Porosity and pore size}

Porosity is commonly defined as the percentage of void space in a so called cellular solid (the scaffold in bone tissue engineering applications) (154). Using solid and porous partic les of hydroxya patite for the delivery of the growth factor BMP-2, Kuboki et al. showed that pores are crucial for bone tissue fomation because they allow migration and proliferation of osteoblasts and mesenchymal cells, as well as vascularisation; no new bone formed on solid particles (155). A porousscaffold surface also improves mechanical interlocking between the implanted TECs and the surrounding natural bone tissue, providing greater mechanical stability at this crucial interface in tissue engineering (156).

Scaffold porosity and pore size relate to the surface area available for the adhesion and growth of cells both in vitro as well as in vivo and to the potential for host tissue ingrowth, including vasculature, to penetrate into the central regions of the scaffold architecture. In assessing the significance of porosity several in vivo studies have been conducted utilising hard scaffold materials such as calcium phosphate or titanium with defined porous characteristics (157). The majority of these studies indicate the importance of pore structure in facilitating bone growth. Increase of porosity as well as pore size and spacing of pore interconnectivity has been found to positively influence bone formation in vivo, which is also correlated with scaffold surface area. Pore interconnections smaller than $100 \mu \mathrm{m}$ were found to restrict vascular penetration and supplementation of a porousstructure with macroscopic channels has been 
found to further enhance tissue penetration and bone formation $(97,158)$. Interestingly, these results correlate well with the diameter of the physiological Haversian systems in bone tissue that possess an approximate diameter of more than $100 \mu \mathrm{m}$. The ability of new capillary blood vessels to grow into the TEC is also related to the pore size, thereby directly influencing the rate of ingrowth of newly formed bone tissue into the TEC: In vivo, larger pore sizes and higher porosity lead to a faster rate of neovascularisation, thereby promoting greater a mounts of new bone formation via direct osteogenesis. In contrast, small pores favour hypoxic conditions and induce osteochondral fomation before osteogenesis occurs (92). Pores and pore interconnections should be at least 300 microns in diameter to allow sufficient vascularisation. Besides the actual macroporosity (pore size $>50 \mu \mathrm{m}$ ) of the scaffold microporosity (pore size < $10 \mu \mathrm{m})$ and pore wall roughness also have a large impact on osteogenic response: Mic roporosity results in larger surface a reas contributing to higher bone-inducing protein adsorption and to ion exchange and bone-like apatite formation by dissolution and re-precipitation $(139,157)$. As outlined above, sub-mic ron and nanometre surface roughness fa vours attachment, proliferation and differentiation of anchorage-dependent bone forming cells (139).

Although increased porosity and higher pore size facilitate bone ingrowth, it also compromises the structural integrity of the scaffold, and if the porosity becomes too high it may adversely affect the mechanical properties of the scaffold at the same time (79). In addition, the rate of degradation is influenced by the porosity and pore size (for biodegradable scaffolds). A higher pore surface area enhances interaction of the scaffold materials with host tissue and can thereby accelerate degradation by macrophages via oxidation and/or hydrolysis (157). Therefore, scaffolds fabricated from biomaterials with a high degradation rate should not have high porosities ( $>90 \%$ ) in order to avoid compromise to the mechanical and structural integrity before adequate substitution by newly formed bone tissue. Scaffolds made from slowly degrading biomaterials with robust mechanical properties can, in contrast, be highly porous (157). Table 4 illustrates mechanical properties and degradation kinetics in relation to the porosity for many commonly used composite scaffolds. This illustrates

Table 4 Mechanical properties and degradation kinetics in relation for porosity ofcomposite scaffolds. Reproduced with permission from (79), Copyright (c) 2007 John Wiley \& Sons, Ltd.

\begin{tabular}{|c|c|c|c|}
\hline Scaffold composites & Mechanical properties & Porosity/\% & Degradation kinetics \\
\hline $\begin{array}{l}\text { Medical grade } \\
\text { polycaprolactone-tricalcium phosphate } \\
\text { (PCL-TCP) }\end{array}$ & $\begin{array}{l}\text { Compressive modulus 6.8 } \mathrm{MPa} \text {; } \\
\text { compressive strength } 1.0 \mathrm{MPa}\end{array}$ & $60-70$ & 24-30 months \\
\hline $\begin{array}{l}\text { Medical grade } \\
\text { poly(L-lactide-co-D,L-lactide)-tric alcium } \\
\text { phosphate (PமШA-TCP) }\end{array}$ & $\begin{array}{l}\text { Compressive modulus 88.6 MPa (dry) and } \\
51.5 \mathrm{MPa} \text { (wet); compressive strength } 3.1 \\
\mathrm{MPa} \text { (dry) and } 1.5 \mathrm{MPa} \text { (wet) }\end{array}$ & $60-70$ & $<24$ months \\
\hline $\begin{array}{l}\text { Poly(lactide-co-glycolide) } \\
\text { (PLGA)-calcium phosphate (CaP) }\end{array}$ & $\begin{array}{l}\text { Compressive strength } 0.16 \mathrm{MPa} \text { (dry) and } \\
0.04 \mathrm{MPa} \text { (wet) conditions }\end{array}$ & $81-91$ & \\
\hline $\begin{array}{l}\text { Poly-lactic acid + phosphate glass } \\
\text { particles }\end{array}$ & $\begin{array}{l}\text { Compressive modulus } 120 \mathrm{kPa} \text {; } \\
\text { compressive strength } 20.1 \mathrm{kPa}\end{array}$ & 97 & \\
\hline $\begin{array}{l}\text { Poly(L-lactic acid) (PШA) and } \\
\text { hydroxyapatite }(\mathrm{HA}) \text { or } \beta \text {-tricalcium } \\
\text { phosphate ( } \beta \text {-TCP) }\end{array}$ & $\begin{array}{l}\text { Longitudinal modulus up to } 1.5 \text { times } \\
\text { higher than the transverse modulus }\end{array}$ & $>80$ & \\
\hline HA-РША & $\begin{array}{l}\text { Elasticity module up to } 10 \mathrm{GPa} \\
\text { compressive strength up to } 140 \mathrm{MPa}\end{array}$ & 0.4 & \\
\hline $\begin{array}{l}\text { Nanohydroxya patite- } \\
\text { collagen-poly(L-lactide) }\end{array}$ & Compressive strength close to $3 \mathrm{MPa}$ & $\begin{array}{l}\text { About } 90 \text { (pore } \\
\text { sizes } 100-300 \mu \mathrm{m})\end{array}$ & $\begin{array}{l}\text { In vitro with a reduction in } \\
\text { mass of } 19.6 \% \text { after } 4 \text { weeks }\end{array}$ \\
\hline $\begin{array}{l}\text { Hydroxya patite/chitosan-gelatin network } \\
\text { (HA-CS-Gel) }\end{array}$ & & 90.6 & \\
\hline $\begin{array}{l}\beta \text {-tricalcium phosphate }(\beta \text {-TCP) matrix } \\
\text { and hydroxyl apatite }(\mathrm{HA}) \text { na nofibres }\end{array}$ & Compressive strength $9.87 \mathrm{MPa}$ & 73 & \\
\hline $\begin{array}{l}\text { Poly(lactide-co-glycolide) mic rospheres } \\
\text { and a poorly crystalline calcium } \\
\text { phosphate }\end{array}$ & $\begin{array}{l}\text { Compressive modulus } 65 \mathrm{MPa} \text { at high } \\
\text { polymerceramic ratio }(3: 2.25)\end{array}$ & & \\
\hline
\end{tabular}


that there are a number of advantages and disadvantages associated with any changes made to the porosity or pore size of scaffolds. It is inevitable to find a balance between these prosand cons in order to tailor the scaffold properties ideally to the demands of the tissue engineering approach used. For comprehensive reviews on role of porosity and pore size in tissue engineering scaffolds, the reader is referred to two recently published reviews $(157,159)$.

It becomes clear that a multitude of factors have to be taken into account when designing and fabricating scaffolds for bone tissue engineening. However, it is beyond the scope of this review to present all of them in detail and a number of comprehensive reviews have been published recently on this topic $(2,5,79,97,101$, 160-161).

\section{Additive manufacturing and Computer Aided Design - Game changers in the fabrication of three-dimensional scaffolds}

The three-dimensional design characteristics in combination with the material properties of a scaffold are crucial for bone tissue engineering purposes. Not only does the scaffold structure need to be controlled on a macroscopic level (to achieve suffic ient interposition of the scaffold into the defect site), but also on a microscopic level (to optimise tissue engineening properties with regards to osteoinduction, osteoconduction, osteogenesis and vasc ularisation as well as mechanic al stability) and even down to nanostructural configuration (to optimise protein adsorption, cell adhesion, differentiation and proliferation related to desired tissue engineening characteristics of the TEC). It is therefore necessary to exert strict control over the scaffold properties during the fabrication process. Conventional tec hniques for scaffold fabrication include solvent casting and particulate leaching, gas foaming, fibre meshes and fibre bonding, phase separation, melt molding, emulsion freeze drying, solution casting and freeze drying (162). All of these techniques a re subtractive in nature, meaning that parts of the fabricated scaffold are removed from the construct after the initial fabrication process in order to generate the desired three-dimensional characteristics. Hence a number of limitations exist regarding these fabrication methods: conventional methods do not allow a precise control over pore size, pore geometry, pore interc onnectivity or spatial distribution of pores and interc onnecting channels of the scaffolds fabricated (92, 163-164). In addition, many of these techniques require the application of organic solvents and their residues can impose severe adverse effects on cells due to their potentially toxic and/or carcinogenic nature, reducing the biocompatibility of the scaffold signific a ntly (165).

The introduction of a dditive manufacturing (AM) techniques into the field of bone tissue engineering has helped to overcome many of these restrictions $(92,162$, 166). In AM three-dimensional objects are created in a computer-controlled layer-by-layer fabrication process. In contrast to subtractive conventional methods of scaffold fabrication, this technique is additive in nature and does not involve removal of materials after the initial fabrication step. These techniques have also been named "rapid prototyping" or "solid free form fabrication" in the past, but in order to clearly distinguish them from conventional methods the latest ASTM standard now summarises all of these techniques under the term "Additive Manufacturing" (167). The basis for each AM process is the design of a three-dimensional digital or in silico model of the scaffold to be produced. This computer model can either be created from scratch using "computer aided design" (CAD) methods or can be generated using data from a 3D-scan of existing three-dimensional struc tures (such as the human skeleton) (168). The digital model is then converted into an ST-file that expresses the three-dimensional structure as the summary of multiple horizontal two-dimensional planes. Using this ST-file an AM-machine then creates the three-dimensional scaffold structure in a layer-bylayer fabrication method in which each layer is tightly connected to the previouslayer to create a solid object. A number of different AM techniques are currently applied using themal, chemical, mechanical and/or optical processes to create the solid three-dimensional object (166). These methods include laser-based methodssuch as Stereolithography (STL) and Selective Laser Sintering (SLS), printing-based applications (e.g. 3D-Printing, WaxPrinting) and Nozzle-based systems like Melt Extrusion/ Fused Deposition Modeling (FDM) and Bioplotting. The multitude of $A M$ techniques and their specifications were reviewed by several a uthors lately $(162,166,169-$ 170).

AM techniques have been used since the 1980s in the telecommunication industry, in jewelry making and production of automobiles (171). From the 1990s onwards, AM was gradually introduced to the medical field as well (172): AM was initially used to fabricate threedimensional models of bone pathologies in orthopaedic maxillofacial neurosurgical applications to plan surgical procedures and for haptic assessment during the surgery itself (173-174). With recent tec hnic al a dvances AM is nowadays applied to make custom-made implants and surgical tools (175) and to fabric ate highly detailed, custom-made three-dimensional models for the indivi- 
dual patient (using data from CT, MRI, SPECT etc.) to plan surgical a pproaches, specific ally locate osteotomy sites, choose the correct implant and to predict functional and cosmetic outcomes of surgenes (176-177). Thereby the operating time as well as the risk of complications has been reduced signific a ntly.

The application of $A M$ in bone tissue engineening represents a highly significant innovation that has drastic cally changes the way scaffolds are being fabricated AM has more or less become the new gold standard for scaffold manufacturing (92). The advantages of rapid prototyping processes include (but are not limited to) increased speed, customisation and efficiency. AM technologies have relatively few process steps and involve little manual interaction, therefore, three-dimensional partscan be manufactured in hours and days instead of weeks and months. The direct nature of AM allows the economical production of customized tissue engineering scaffolds. The productscan be tailored to match the patient's needs and still sustain economic viability as compared to traditional techniques which must manufacture great numbers of devices. The conventional scaffold fabrication methods commonly limit the ability to form complex geometries and intemal features. AM methods reduce the design constraints and enable the fabrication of desired delic ate features both inside and outside the scaffold. Using ST, the AM technique with the highest precision, for example objects at a scale of $20 \mu \mathrm{m}$ can be fabricated (178). A two-photon STL-technique to initiate the polymerisation can be used to pro- duce structures even at mic rometer and sub-mic rometer levels (179).

AM methods allow for va riation of composition of two or more materials a cross the surface, interface, or bulk of the scaffold during the manufacturing. Thereby, positional variations in physicochemical properties and surface characteristics can be created and utilized to promote locally specific tissue engineering signals. Several AM techniques operate without the use of toxic organic solvents. This is a significant benefit, since incomplete removal of solvents may lead to harmful residues that can affect adherence of cells, activity of incorporated biological agents or surrounding tissues as already described. AM allows the control of scaffold porosity leading to the applications that may have areas of greater or lesser struc tural integrity and a reas of encouraged blood flow due to increased porosity. Fabricating devices and/or implants with differences in spatial distribution of porosities, pore sizes, mechanical and chemical properties can mimic the complex composition and architecture of natural bone tissue and thereby optimise bone tissue engineening techniques. In addition, scaffolds with gradients in porosity and pore sizes can be functionalised to allow vascularisation and direct osteogenesis in one area of the scaffold, while promoting osteochondral ossific ation in the other, which is an appealing approach to reproduce multiple tissues and tissue interfaces within one and the same biomaterial scaffold (157). Table 5 summarises the advantages of scaffolds designed and fabricated by AM techniques.

Table 5 Advantages of scaffolds designed and fabricated via additive manufacturing

\begin{tabular}{|c|c|}
\hline Properties & Advantages \\
\hline Variability & Higher variability of designing a targeted degradability and resorbility as well as improved biocompatiblity \\
\hline Fomability & Can be processed into various shapes, volumes and microstructures \\
\hline Practicability & $\begin{array}{l}\text { Easily mass-produced or propertiescan be tailored for patient-specific applications (addressing the scheme } \\
\text { of Personalised Medicine) }\end{array}$ \\
\hline Controllability & $\begin{array}{l}\text { Control over chemical and physically structural properties, crysta llinity, hydrophobicity, degradation rate } \\
\text { and mechanical properties (e.g. through the alteration of surface chemistry) }\end{array}$ \\
\hline Applicability & Allow exact engineering of matrix configuration, satisfying the biophysical limitations of mass transfer \\
\hline Flexibility & $\begin{array}{l}\text { Flexibility to alter the physical properties and potentially facilitate reproducibility and scale-up } \\
\text { Flexibility to manipulate the configuration of matrix to vary the surface area available forcell attachments, } \\
\text { also to optimize the exposure of attached cells to nutrients and allow transport of waste products }\end{array}$ \\
\hline Design & $\begin{array}{l}\text { The designs and fabrication of composite scaffolds which chemical environment sumounding a synthetic } \\
\text { degradable polymermaterial (e.g. aliphatic polyesters) be affected in a controlled fashion as the polymer } \\
\text { by-products are neutralized by ceramic components }\end{array}$ \\
\hline Mass delivery & $\begin{array}{l}\text { The potential to deliver continuously the nutrients and homones that can be incorporated into the scaffold } \\
\text { structure }\end{array}$ \\
\hline Surface properties & $\begin{array}{l}\text { The ratio of surface area to mass can be altered or the porosity, pore size and pore size distribution of the } \\
\text { differing configurationscan be altered so as to increase or decrease the mechanical properties of the } \\
\text { scaffold }\end{array}$ \\
\hline
\end{tabular}




\section{Translating bone tissue engineering strategies from bench to bedside}

Musculoskeletal conditions are highly prevalent and cause a large amount of pain, illness and disability to patients. These conditions are the second most common reason for consulting a general practitioner, accounting for a lmost $25 \%$ of the total cost of illness and up to $15 \%$ of primary care (180). In addition, the impact of musculoskeletal conditions is predicted to grow with the increasing incidence of lifestyle-related obesity, reduced physical fitness and increased road traffic accidents (180). The impact of bone trauma is significant-the consequences of failing to restore full function to an injured limb are dramatic ally demonstrated by the statistic that only $28 \%$ of patients suffering from severe open fractures of the tibia are able to resume full function and hence retum to previous employment (180). Along with trauma, tumour resection is a nother major cause of large bone defects. Cancer is a major public health challenge, with one in four deaths in the United States currently due to this disease. Recent statistics indicate that 1638910 new c ancer cases and 577190 deaths from cancer are projected to occur in the United States in 2012 (181). As outlined above, the number of procedures requining bone implant material is increasing, and will continue to do so in our aging population and with deteriorating physical activity levels (57). The current bone grafting market a lrea dy is estima ted to be in exc ess of $\$ 2.5$ billion each yearand is expected to increase by $7-8 \%$ per year (45). With the introduction of tissue engineering the hopes and expectations were extremely high to be able to substitute natural organs with similar (or even better) tissue engineered replacement organs. However, at the time it was stated that "few areas of technology will require more interdisciplinary research than tissue engineering" (75) and this assessment holds true today.

In the years to follow, numerous private and public institutes conducted scientific research and clinic al trans lation efforts related to tissue engineering. At the beginning of 2001, tissue engineering research and development was being pursued by 3300 scientists and support staff in more than 70 start-up companies or business units with a combined annual expenditure of over $\$ 600$ million USD (182). The US National Institutes of Health (NIH), accounting for the largest cumulative US federal research expenditures, has increased the funding in tissue engineering from 2.36 billion USD in the fiscal year 2003 to more than 614 billion USD for the fisc al year 2006 (183). Between 2000 and 2008 the number of papers published on tissue engineering and scaffolds per year increased by more than $400 \%$ and more than $900 \%$, respectively
(184). But despite the increasing research expenditure and the magnitude of discoveries and innovations in bone tissue engineering since its introduction more than three decades ago, the translation of these novel techniques into routine clinical applications on a large scale has still not taken place. As Scott J. Hollister has pointed out, there is, on the one hand, a stark contrast between the a mount of tissue engineering research expenditures over the last 20 years and the resulting numbers of products and sales figures. On the other hand, there is also a significant discrepancy between the complexities of intended tissue engineering therapies compared to the actual thera pies that have reached clinic al a pplic ations (184). This evident gap between research and clinical applic ation/commercialisation is commonly termed the "Valley of Death" due to the large number of ventures that "die" between scientific technology development and actual commercialization due to lack of funds (Figure 4) (184). The Valley of Death is partic ularly large for tissue engineening approaches because this field of research often utilises immensely cost intensive high-tech biotechnologies for technologic al development eating up large parts of the funding available, but then additionally faces the challenges of funding large scale preclinic al studies and clinical studies to gain approval by regula tory bodies, demonstrate product safety and ga in clinic al acceptance (184-186).

Bridging the gap between tissue engineering research and clinic al a pplic ations

To bridge the gap between the bench and bedside, the scaffold is required to perform as a developmentally conducive extracellular niche, at a clinically relevant scale and in concordance with strict clinical (economic and manufacturing) prerequisites (Figure 5) (187). In this context the scaffold facilitates for smaller and medium sized defects the entrapment of the hematoma and prevents it's "too early" contraction (188). For large and high-load bearing defects the scaffold can also deliver cells and/or growth factors to the site of damage and provides an appropriate template for new tissue formation. The scaffold should thus constitute a dynamically long-lasting yet degra dable three-dimensional architecture, preferably serving as a functional tissue substitute which, over time, can be replaced by cell-derived tissue function. Designing and manufacturing processes are believed to be the gatekeepers to transla te tissue engineening research into clinical tissue engineering applications and concentration on the development of these entities will enable scaffolds to bridge the gap between research and clinical practice (184). One of the greatest diffic ulties in bridging the Valley of Death is to develop 
good manufacturing processes and scalable designs and to apply these in preclinical studies; for a description of the rationale and road map of how our multid isc iplinary research team has addressed this first step to translate orthopaedic bone engineering from bench to bedside see below and refer to our recent publication (185). In order to take bone tissue engineening approaches from bench to bedside, it also imperative to meticulously assess the clinic al demands for specific scaffold characteristic sto achieve a broad and optimised range of clinical applic ations for the specific tissue engineering approach. A sophisticated bone tissue engineening technology will not necessa rily have multiple clinical applications just because of its level of complexity, and defining specific clinical target applications remains one of the most underestimated challenges in the bridging the Valley of Death (184). There is often a great level of dis crepancy between the clinical demands on a tissue engineering technique and the scientific realisation of such technique, hampering the clinical translation. Thus a scaffold that is realistically targeted at bridging the Valley of Death should (187): (i) meet FDA approval (for further details on this topic s see reviews by Scott J. Hollister 2011 and 2009) (184, 189); (ii) a llow for cost effective manufacturing processes; (iii) be sterilisable by industrial techniques; (iv) enable easy handling without extensive preparatory procedures in the operation theatre; (v) preferably, be radiographically distinguishable from newly formed tissue; and (vi) allow minimally invasive implantation (190-191).

Rationale for translating bone tissue engineering strategies into clinical applications In targeting the translation of a (bone) tissue engineering approach from bench to bedside, there is a distinct hierarchy and sequence of the type of studies that need to be undertaken to promote the translation process (192): Having identified clinic al needs and based on fun-

\section{Valley of Death Funding: Venture Capital?, SBIR?, Corporate Partnerships?}

\section{Basic Research Funding:} NIH, NSF, DOD, etc.

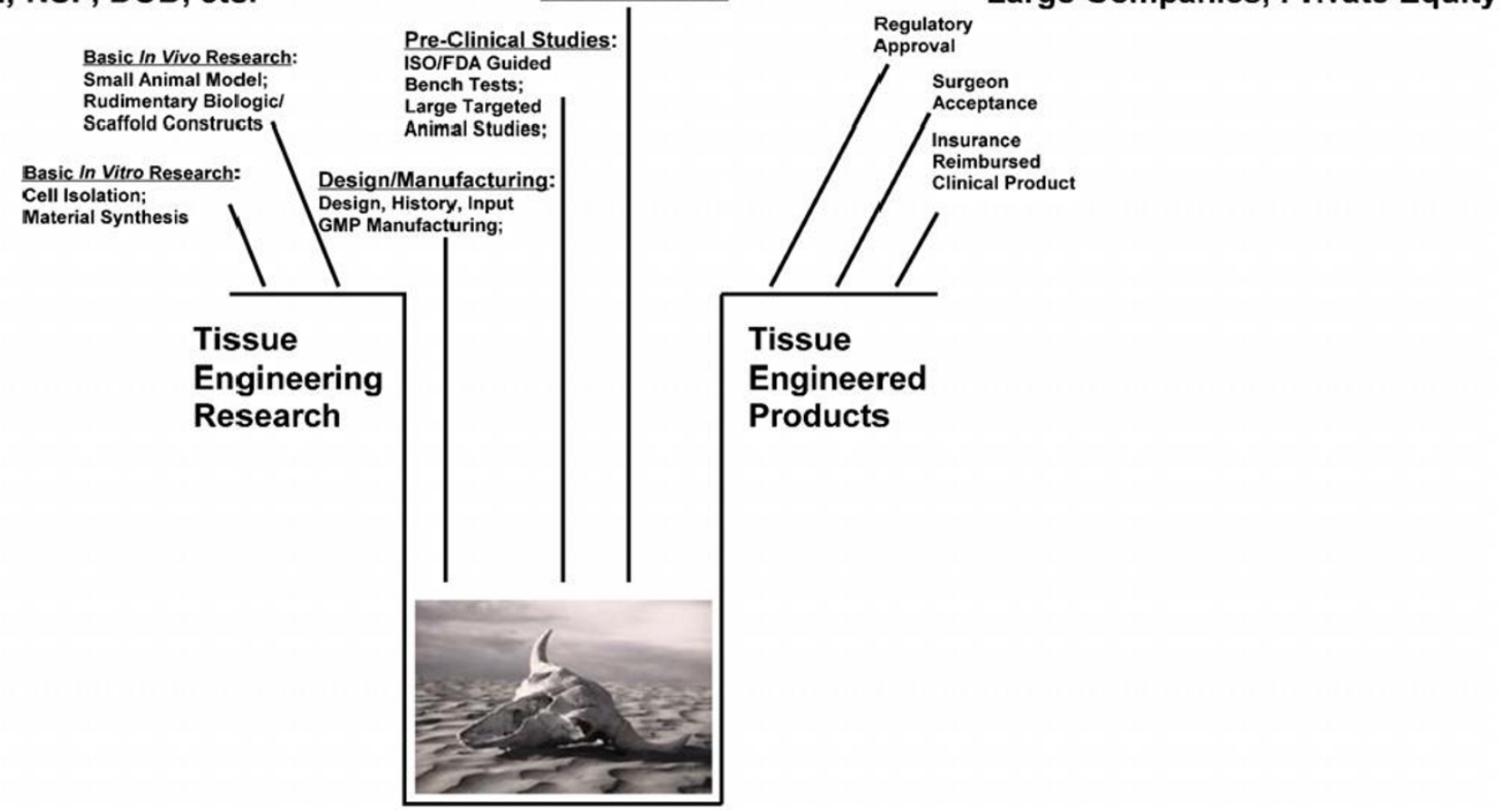

The Valley of Death

Figure 4 For tissue engineering, the Valley of Death is the gap and associated funding difficulties of taking tissue engineering technologies to tissue-engineered products. The Valley exists due to the need of obtaining funding to develop scalable/GMP design and manufacturing processes, the need for pre-clinical studies proving therapies in large animal models, and finally, the need to progress to clinical trials. Reproduced with permission from (184), (C) 2009 IOP Publishing Ltd. 


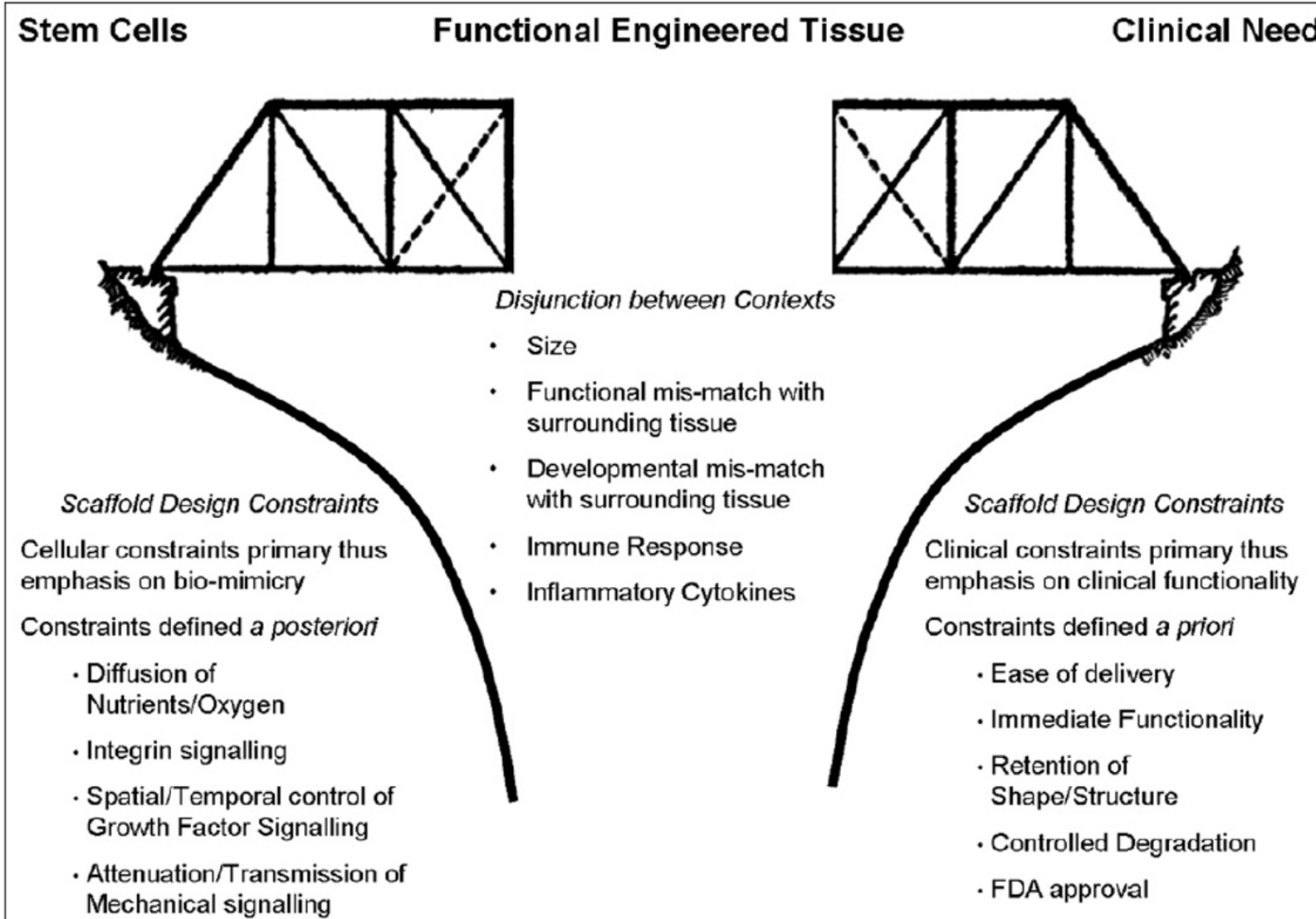

Developmental Context

Adult Context

Figure 5 Bone tissue engineering strategies rely on three-dimensional scaffolds that constitute an inductive/conductive extracellular microenvironment for stem cell function as well as a delivery vehicle and 3D scaffold of clinically relevant properties and proportions. In fulfilling these dual criteria the biomimetic scaffold plays a critical role bridging the gap between the developmental context of stem cell mediated tissue formation and the adult context of injury and disease. Reproduced with permission from (187), (c) 2008 Elsevier Inc.

damental disc overies regarding biological mechanisms, a novel tissue engineering approach is designed and first studies are undertaken to characterise mechanical and chemical properties of the TEC to be used. The next step involves feasibility and bioactivity testing and should be camied out in vitro and in vivo. In vitro assays using cell culture preparations are used to characterise the effects of materials on isolated cell function and for screening large numbers of compounds for biological activity, toxic ity and immunogenic ity (193-194). However, due to their nature using isolated cells, in vitro models are una voidably limited in their capacity to reflect complex in vivo environments that the TEC will be exposed to and are therefore inadequate to predict in vivo or clinical performances. Therefore, in vivo models (that is a nimal models) are required in order to overcome the limitations of in vitro models to provide a reproducible approximation of the real life situation. In vivo feasibility testing is a lmost exc lusively done in small a nimals, ma inly in rodents and rabbits (192, 195-197). The advantages of small a nimal models include rela tively easy standardisation of experimental conditions, fast bone tumover rates (=shorter periods of observation), similar lamellar bone architecture and similar cancellous bone thinning and fragility, similar remodelling rates and sites, common availability and relatively low costs for housing and maintenance. Disadvantages of rodent and rabbit models include different skeletal loading pattems, open epiphyses at various growth plates up to the age of 12-14 months (or for lifetime in rats), minimal intra-cortical remodelling, the lack of Harversian canal systems, a smaller proportion of cancellous bone to total bone mass and their relatively small size for testing of implants (196). Whilst a large number of studies in rodents and rabbits have established proof of concept for bone tissue engineening strategies, scaling up to larger, more clinically 
relevant animal models has presented new challenges. Quoting Thomas A. Einhom, when conducting animal studies, one has to keep in mind that "in general, the best model system is the one which most closely mimics the clinical situation for which this technology is being developed, will not heal spontaneously unless the technology is used, and will not heal when another technology is used if that technology is less advanced than the one being tested" (198). The most effective animal models will therefore 1 ) provide close resemblance of the clinical and biological environment and material properties, 2) encompass highly standardised measurement methods providing objective parameters (qualitative and quantitative) to investigate the newly formed bone tissue and 3) are able to detect and predict significant differences between the bone tissue engineering methods investigated (192). For clinical modelling and efficacy prediction of the tissue engineening strategy to be translated into clinical application, up-scaling to large a nimal models is therefore inevitable. Thereby, the tissue engineering therapy can be delivered in the same (or similar) way in which it will be delivered in clinical settings utilising surgical techniques that match (or closely resemble) clinical methods at the site that matches the setting in which it will be used later as closely as possible (192). The advantage of large animal models (using nonhuman primates, dogs, cats, sheep, goats, pigs) is the closer resemblance of microarchitecture, bone physiology and biomechanical properties in humans. They encompass a well-developed Haversian and trabecular bone remodelling, have greater skeletal surface to volume areas, show similar skeletal disuse atrophy, enable the use of implants and techniques similar to the ones used in humans and show highly localised bone fragility associated with stress shielding by implants. However, the use of large animal models has disadvantages as well, including the high cost and maintenance expenses, extensive housing and space requirements, relatively long life spans and lower bone tumover rates (making longer study periods necessary), diffic ulties in standardisation to generate large, homogenous samples for statistical testing as well as various ethical concems depending on the species used (e.g. primates) (196). But despite several disa dvantages, it is inevitable to perform the final pre-clinical in large animals, as realistically as possible, with relevant loading conditionsand with similar surgic al techniquesas used in the final procedure in humans (197). Large animal models provide mass and volume challenges for scaffold-based tissue engineening and require surgic al fixation tec hniques that cannot be tested either in vitro or in small animal models (184). In general, preclinical translation testing is performed in large skeletally mature animals, the species most utilised are dog, sheep, goat and pig $(192,199)$. If suffic ient prec linic al evidence for the effic acy and safety of the new bone tissue engineering system has been generated utilising large animal models, clinical trials care undertaken to prove clinical signific ance and safety, ultimately leading to the translation of the technology into routine clinical practice.

Taking composite scaffold based bone tissue engineering from bench to bedside

In accordance with the above outline rationale for translating bone tissue engineering research into clinical applic ations, during the last decade our interdisciplinary research team has focussed on the bench to bedside translation of a bone tissue engineering concept based on slowly biodegradable composite scaffolds made from medical grade polycaprolactone (MPCL) and calcium phosphates [hydroxyapatite (HA) and tricalcium phosphate (TCP)] $(80,200)$. Detailed descriptions of the scaffold fabrication protocolcan be found in our recent public ations (102, 109, 200-202).

The scaffolds have been shown in vitro to support cell attachment, migration and proliferation; degradation behaviour and tissue in-growth has also been extensively studied (203-206). We subsequently took the next step towards clinical translation by performing small animal studies using rat, mice and rabbit models (207209). As reviewed in detail in Reference (200), we were able to demonstrate the in vivo capability of our composite scaffolds in combination with growth factors or cells to promote bone regeneration within ectopic sites or critic al sized cranial defects in the small animal models. Studies in large a nimal models that closely resemble the c linic al c ha ractenistic s of human disea se, with respect to defect size and mechanical loading, then became essential to advance the translation of this technology into the most diffic ult and challenging clinical applications in orthopaedic tumour and trauma surgery. The choice of a suitable large animal model dependson the ultimate clinical application, and consequently there is no such thing as "one gold standard animal model". Over the last years, our research team has investigated the application of our composite scaffolds in several preclinical large animal models addressing different clinic al a pplic ations:

Load-bea ring, critic al-sized ovine tibial defect model Well-characterised, reproducible and clinically relevant animal models are essential to generate proof-ofprinciple pre-clinical data necessary to advance novel therapeutic strategies into clinical trial and practical 
application. Our research group at the Queensland University of Technology (QUT; Brisbane, Australia) has spent the last 5 years developing a world-leading defect model to study pre-clinic ally different treatment options for cases of large volume segmental bone loss $(159,210)$. We have successfully established this $3 \mathrm{~cm}$ critical-sized defect model in sheep tibiae to study the MPCL-TCP scaffold in combination with cells or growth factors including bone morphogenic proteins (BMPs) (211-212). This model has not only generated a series of highly cited public ations (211-215), but also has sttracted large interest in the orthopaedic industry to be used as a preclinical test bed for their bone graft products under development. The model enables control of experimental conditions to allow for direct comparison of products against a library of benchmarks and gold standards we have developed over the last 5 years (we have performed more than 200 operations using this model todate). Our preclinical tibial defect model developed at QUT is one of the only available models intemationally, which is suitable from both reproducibility and cost point of view for the evaluation of large segmental defect repa ir technologies in statistic ally powered study designs. We have chosen this critical sized segmental defect model of the tibia for our large a nimal model because tibial fractures represent the most common long bone fractures in humans and are often associated with significant loss of bone substance (216-217). Also, tibial fractures result in high rates of non-unions or pseudarthroses $(216,218)$. From an orthopaedic surgeons point of view it can be argued that amongst all bone defects seen in the clinical practice, segmental defects of the tibia are often the most challenging graft sites. This owes to the grafts being required to bear loads close to physiological levels very soon after implantation, this is despite intemal fixation, which often provides the necessary early stability, but also suffers from the poor soft tissue coverage (vascularisation issue) of the tibia compared to the femur. Hence, in a bone engineering strategy for the treatment of segmental tibial defects, the scaffold must bear (or share) substantial loads immediately after implantation. The scaffold's mechanical properties (strength, modulus, toughness, and ductility) are determined both by the material properties of the bulk material and by its structure (macrostructure, mic rostructure, and nanostructure). Matching the mechanical properties of a scaffold to the tibial graft environment is critic ally important so that progression of tissue healing is not limited by mechanical failure of the scaffold prior to successful tissue regeneration. Similarly, because mechanical signals are important mediators of the differentiation of cell progenitors, a scaffold must create an appropriate stress environment throughout the site where new tissue is desired. Hence, one of the greatest challenges in scaffold design for load bearing tibial defects is the control of the mechanical properties of the scaffold over time. By trialing our bone tissue engineering strategies in a tibial defect model, we will therefore address a highly relevant clinical problem and are creating valuable pre-clinical evidence for the translation from bench to bedside. With the $3 \mathrm{~cm}$ critical defect being regenerated successfully by applying our MPCL-TCP scaffold in combination with BMP (102), we are now investigating bone regeneration potentials in even larger sized tibial defects (Figure 6).

Minimally-invasive ovine thoracic spine fusion model Spinal fusion has been investigated in a nimal models for one hundred years now and a lot of the knowledge we have today on how spinal fusion progresses was gained through animal models (219-220). With regards to the above pictured rationale for translating bone tissue engineering approaches to clinical practice, it is of importance to note that the physical size of the sheep spine is adequate to allow spinal surgery to be camied out using the same implants and surgical approaches that are used in humans as well. Also, sheep spines allow for an evaluation of the success of the study using fusion assessments commonly used in clinical practice. When considering spinal fusion in large animal models, it is apparent that due to the biomechanical properties of the spine a biped primate animal model [such as in (221)] should ideally preferred over a quadruped large a nimal model [for example ovine (222) or porc ine (223)]. But given the expenses and limited availability of primate testing as well as ethic al concems due to the close phylogenical relation, it is more feasible to trial large numbers of scaffold variations in the most appropriate quadruped large animal models and then evaluate the best performing scaffold in a primate model, if possible (184).

We have outlined above that defining specific clinical target applic ations is a critic al prerequisite for suc cessful bone tissue engineening research that is meant to be translated into clinical practice. In accordance with this we have selected the thoracic spine for our animal model because we have identified idiopathic scoliosis as clinically highly relevant thoracic spine pathology. Idiopathic scoliosis is a complex three-dimensional deformity affecting $2-3 \%$ of the general population (224). Scoliotic spine deformities include progressive coronal curvature, hypokyphosis or lordosis in the thoracic spine and vertebral rotation in the axial plane with posterior elements tumed rotated toward the curve concavity. 
Scoliotically deformed vertebral columns are prone to accelerated intervertebral disc degeneration, initiating more severe morphological changes of the affected vertebral joints and leading to chronic local, pseudoradicular, and radicular back pain (225). One of the critic al a spects in surgic al scoliosis deformity correc tion is bony fusion to achieve long-term stability (226). Autologous bone grafting is still the gold standard to achieve spinal fusion and superior to other bone grafts for spinal fusion (227-229). Nonetheless, the use of autologous bone grafting material has signific ant risks as outlined in detail above. A number of a nimal models for the use of tissue-engineered bone constructs in spinal fusion exists (230) and the use of bone morphogenetic proteins for spinal fusion has been studied extensively $(219,222$, 231-232). However, to the best of our knowledge, our ovine thoracic spine fusion model is the first existing preclinical large animal model on thoracic interverte- bral fusion allowing the assessment of tissue-engineering constructs such as biodegradable MPCL-CaP scaffolds and recombinant human bone morphogenetic protein2 (hBMP2) as a bone graft substitute to promote bony fusion (Figure 7) (233). We have been able to show that radiological and histological results at 6-months post surgery ind ic ated had comparable grades of fusion and evidenced new bone formation for the MPCL-CaP scaffolds plus rhBMP-2 and autograft groups. The scaffold alone group, however, had lower grades of fusion in comparison to the other two groups. Our results demons trate the ability of this large a nimal model to trial various tissue engineering constructs against the current gold standard autograft treatment for spinal fusion in the same animal. In the future, we will be able to compare spinal fusion tissue engineering constructs in order to create sta tistic ally signific ant evidence for clinical translation of such techniques.
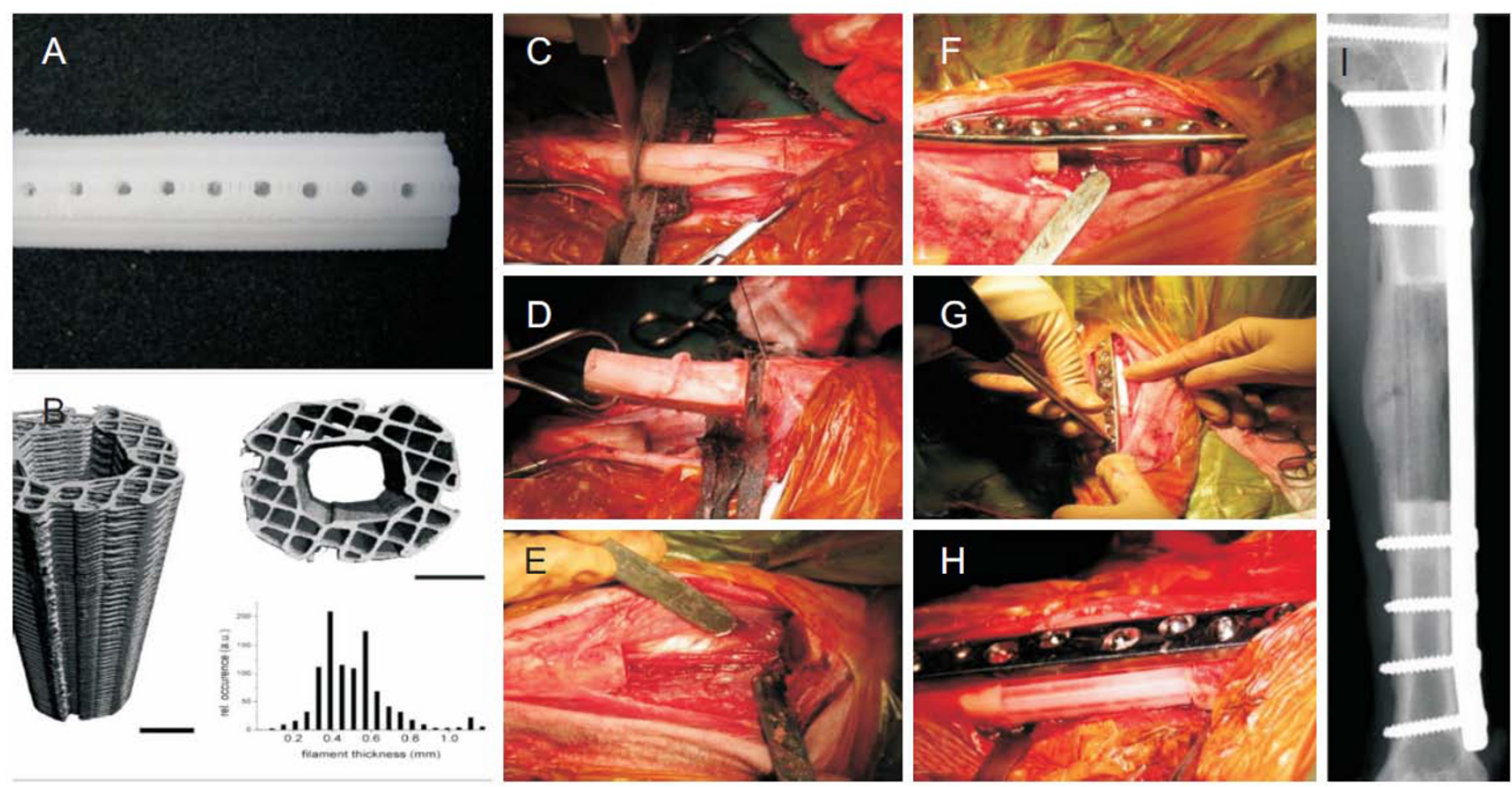

Figure 6 Load-bearing critical-sized ovine tibial defect model using mPCL-TCP scaffolds manufactured by FDM. Scaffolds (A=clinical image, holes are oriented towards neurovascular bundle to further promote ingrowth of vasculature) exhibit mechanical and structural properties comparable to cancellous bone and can be produced with distinct control over scaffold properties (porosity, pore size, interconnections etc.) by AM. B= Side and top view of a mPCL-TCP scaffold visualised by microcomputed tomography. The fabrication via FDM enables well-controlled architecture as evidenced by the narrow filament thickness distribution, leading to a porosity (volume fraction available for tissue ingrowth) of $60 \%$, with interconnected pores. Scale bars are $5 \mathrm{~mm}$. [Image B reproduced with permission from (246), ( $)$ The Authors.] C-H = Surgical procedure: A $6 \mathrm{~cm}$ tibial defects is created in the tibial diaphysis (C-D) and the periosteum is removed from the defect site and additionally also from $1 \mathrm{~cm}$ of the adjacent bone proximally and distally. Special care is taken not to damage the adjacent neurovascular bundle (E, bundle indicated by Asterisk). The defect site is then stabilised using a 12 hole DCP (Synthes) (F). Afterwards 6cm mPCL-TCP scaffold loaded with PRP and rhBMP-7 is press fitted into the defect site to bridge the defect $(\mathrm{G}-\mathrm{H})$ and the plate is fixed in its final position. Xray analysis at 3 months after implantation (I) shows complete bridging of the defect site with newly formed radio-opaque mineralised tissue (in order to provide sufficient mechanical support, the scaffold is not fully degraded yet and scaffold struts appear as void inside the newly formed bone tissue). 

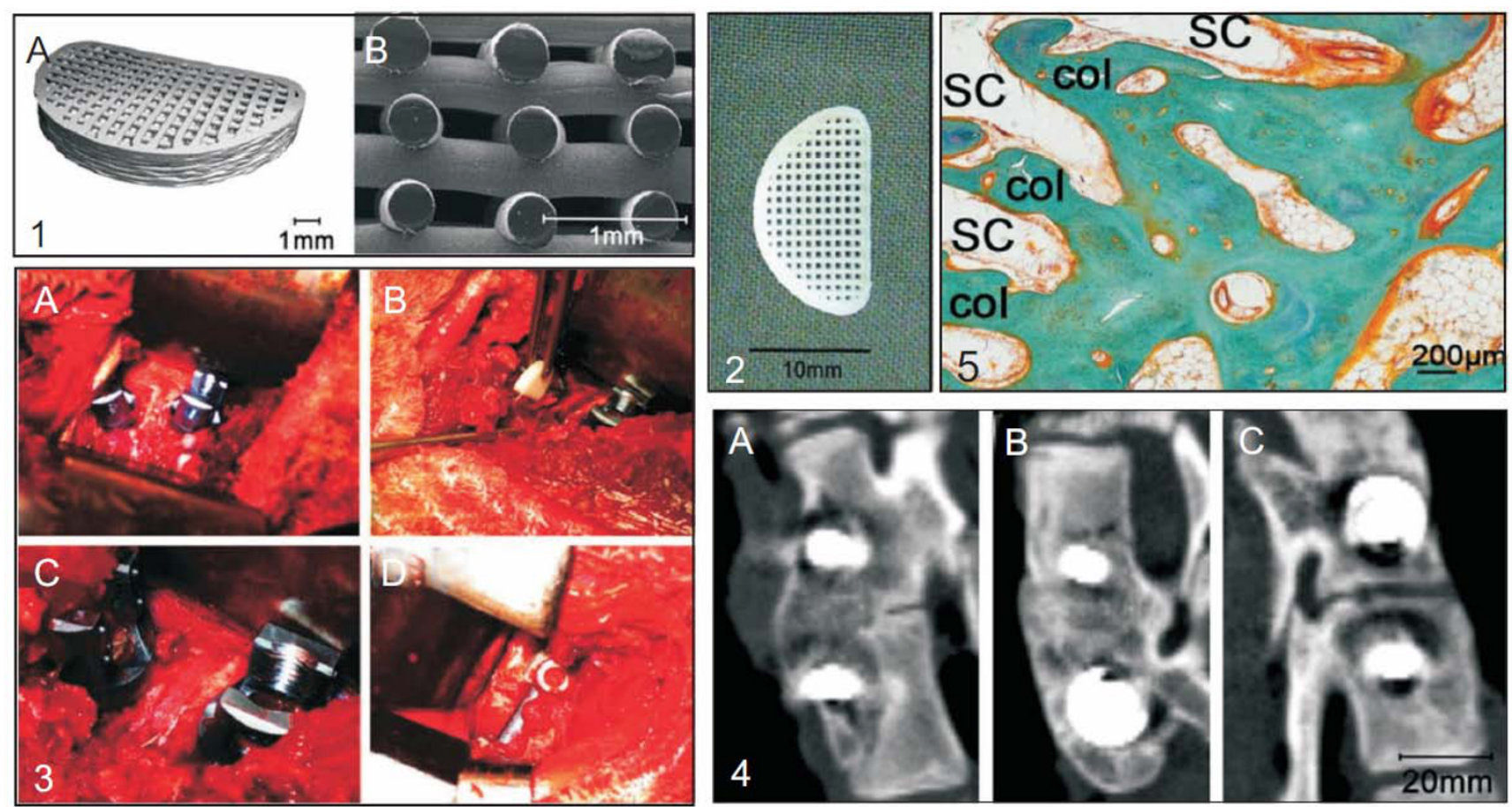

Figure 7 The use of mPCL-CaP scaffolds for spinal fusion. (1) (A) Micro-computed tomography (m-CT) image of a biodegradable mPCL-TCP scaffold. (B) Representative scanning electron microscopy image at 100xmagnification. (2) Image of scaffold prior to implantation. (3) Pictorial series demonstrating the implantation process of a PCL-based scaffold: (A) Cleared intervertebral disc space prepared for implantation. (B) Implantation process of scaffold into prepared intervertebral disc space. Scaffold being inserted into prepared intervertebral space. (C) Scaffold in situ within a predefined intervertebral disc space. (D) Internal fixation with a $5.5 \mathrm{~mm}$ titanium rod and two vertebral screws stabilize the treatment level. (4) Representative reconstructed parasagittal CT images at 6 months demonstrating radiologically evident high fusion levels of (A) the recombinant human bone morphogenetic protein-2 (rhBMP-2) plus calcium phosphate (CaP)-coated PCLbased scaffold and (B) autograft groups, while lower fusion levels were seen in the (C) CaP-coated PCL-based scaffold alone group. (5) Representative histological (longitudinal) sections of specimen at 6 months post surgery from PCL-based scaffold plus rhBMP-2 group exhibiting well aligned columns of mineralized bone (indicated by letters "col") seen interdigitating with struts of the scaffold filaments (indicated by letters "SC"). Reproduced with permission from (233), ( ) Mary Ann Liebert, Inc.

Current clinical applications of the composite scaffolds and future outlook

The interdisciplinary research group has evaluated and patented the parameters necessary to process medical grade polycaprolactone (mPCL) and $\mathrm{mPCL}$ composite scaffolds (containing hydroxyapatite or tricalciumphosphate) by fused deposition modeling (97). These "first generation scaffolds" have undergone more than 5 years of studies in clinical settings and have gained Federal Drug Administration (FDA)-approval in 2006 and have also been successfully commercialised (www. osteoporeintemational.com). The scaffolds have been used highly successfully as burr whole plugs for cranioplasty (234) and until today more than 200 patients have received bur whole plugs, scaffolds for orbital floor reconstruction and other cranioplasties (Figure 8) (92). With their extensive, multidisciplinary approach the research team has achieved one of the rare examples of a highly successful bone tissue engineering approach bridging the gap between scientific research and clinical practice leading to signific ant innovations in clinic al routines.

As shown above, "second generation scaffolds" produced by FDM and based on composite materials have already been broadly studied in vitro plus in vivo in small animal models and are currently under preclinical evaluation in large animal studies conducted by our research group. Available data so far clearly supports the view that further translation into clinical use will take place and that a broad spectrum of targeted clinical applic ations will exist for these novel techniques.

Our results are consistent with the results of other members of the (bone) tissue engineering community all around the world, clearly showing the significance of innovations in the field of tissue engineening. In 2006 Chris Mason proposed two distinctly different periods of the regenerative medicine industry, namely, Regenerative Medicine 1.0 spanning 1985-2002, and Regenerative Medicine 2.0 commencing in approximately 2006 (1). 
We herein propose that Regenerative Medic ine 3.0 has commenced. We foresee that the complexity and great variety of large bone defects require an individualized, patient-specific approach with regards to surgical reconstruction in general and implant/tissue engineening selection in specific. We advocate that bone tissue engineering and bioengineering technology platforms, such as additive manufacturing approaches can be used even more substantially in bone grafting procedures to advance clinical approaches in general and for the benefit of individual patient in particular.

The tremendous advantage of scaffolds made by Additive Manufacturing techniques such as Fused Deposition Modeling (FDM) is the distinct control over the macroscopic and microscopic shape of the scaffold and thereby control over the shape of the entire TEC in total. Additive manufacturing enables the fabrication of highly structured scaffolds to optimise properties highly relevant in bone tissue engineering (osteoconductivity, osteo induc tivity, osteogenic ity, vascularisation, mechanical and chemical properties) on a mic ro-and nanometre scale. Using high-resolution medical images of bone pathologies (acquired via $C T, \mu C T, M R I$, ultrasound, 3D digital photogrammy and other techniques) (168), we are not only be able to fabricate patient-specific instrumentation (235-237), patient-specific conventional implants (238-242) or allografts (243), but also to realise custom-made tissue engineering constructs (TEC) tailored specific ally to the needs of each individual patient and the desired clinical application (168, 174, 244). We therefore predict that the commencing area of Regenerative Medicine 3.0 will hold a signific ant leap forward in terms of Personalised Medic ine.

We have already proven the clinical application of
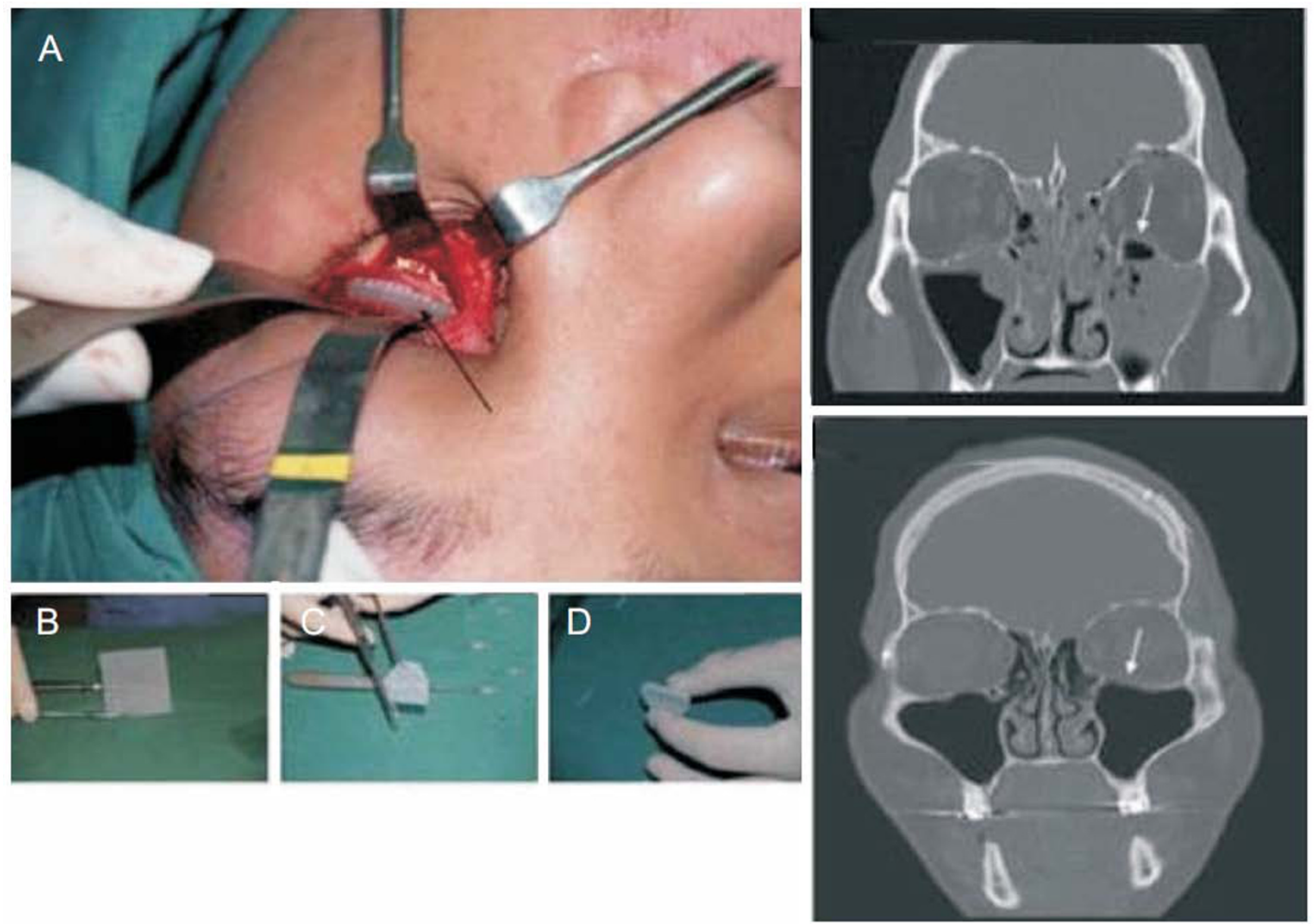

Figure 8 Clinical case showing the craniofacial scaffold applications for orbital floor fractures. Moldable scaffolds (A-D) are used and mechanical stability, early vascularisation, osteoconductivity and ease of handling have been well balanced in the design of mPCL scaffold sheets in order to properly meet the clinician's needs. The clinical follow up 2.5 years postsurgery (lower CT image) of a patient receiving a mPCL scaffold (defect site shown in upper CT image) for the reconstruction of a orbital floor fracture defect showed complete bone regeneration of the defect site (arrow). Reproduced with permission from (92), ㄷ 2007 John Wiley and Sons. 
this concept by fabricating a custom-made bioactive mPCL-TCP implant via CAD/FDM that was used clinic ally to succesffully reconstruct a complex cranial defect (245). We have also recently provided a rationale for the use of CAD/FDM and MPCL-TCP scaffolds in contributing to clinic al therapy concepts after resection of musculoskeletal sarc oma (Figures 9 and 10) (246). Although it has to be mentioned that our approaches presented in this review are at different stages of clinic al translation, their entity clearly represents a promising and highly significant 21 century approach in taking bone tissue engineering strategies from bench to bedside and into the era of Regenerative Medic ine 3.0.

\section{Conclusions}

In conclusion, the field of bone tissue engineering has signific antly changed the millennia old quest by humans
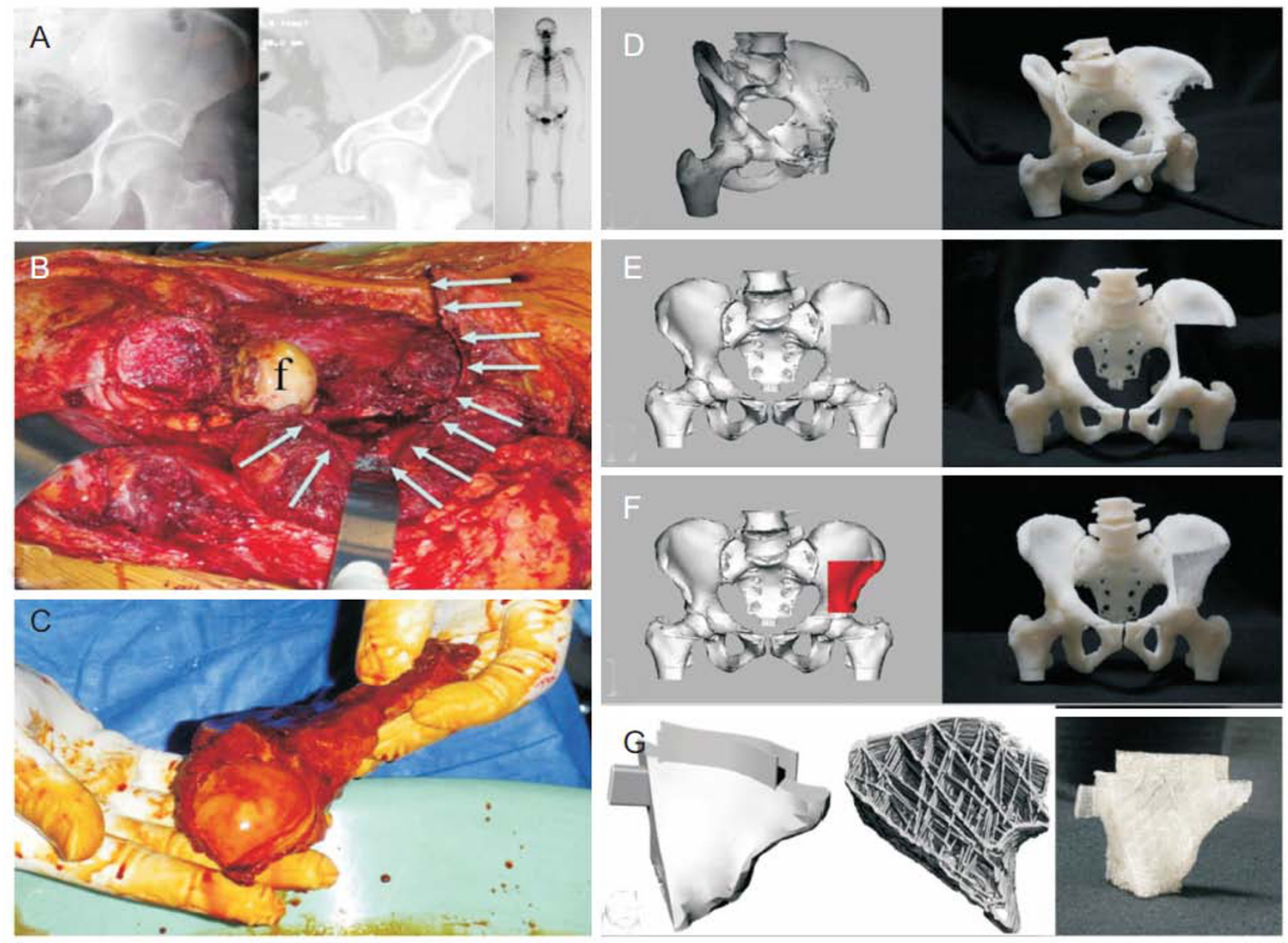

Figure 9 Clinical case of a 52 year old man with a malignant bone tumour above his left hip. (A) X ray and computed tomogram showing mixed lytic sclerotic lesion above the left acetabulum, Technitium-MDP bone scan demonstrating focal area of increased tracer uptake within the tumour. (B) Tumour resection leaving a large pelvic defect (white arrows), $\mathrm{f}=$ femoral head. (C) Resected specimen including upper part of acetabulum (Clinical images: P.F.C.). The surgical resection creates a large bone defect in the pelvis that necessitates the use of autograft/allograft bone material and/or orthopaedic implants to reconstitute the pelvic anatomy. A novel approach (D-G) could be the use of custom made porous bone tissue engineering scaffolds fabricated via Computer Aided Design (CAD) to regenerate such defects: Data obtained from high-resolution CT can be used to create a 3D computer-aided designed (CAD) model of the patient's pelvis by additive manufacturing (D). This model can be used by the orthopaedic surgeon to indicate osteotomy planes to achieve tumour free margins, after which, after which the CAD model is virtually resected (E). A custom made scaffold to fit the defined defect is then created by mirroring the healthy side of the pelvis, adjusting the size of the scaffold accordingly and fabricating the scaffold from the virtual model using AM techniques (F). Flanges, intramedullary pegs and other details can be added to the porous scaffold structure to facilitate surgical fixation and to enhance its primary stability after implantation (G). Images D-G reproduced with permission from (246), ( $)$ The authors

uww.boneresearch.org | Bone Research 
to optimise the treatment of bone defects and to identify suitable bone substitute materials. We have reviewed the historic development, current clinical therapy standard s and their limita tions as well as currently a vailable bone substitute materials. We have also outlined current knowledge on scaffold properties required for
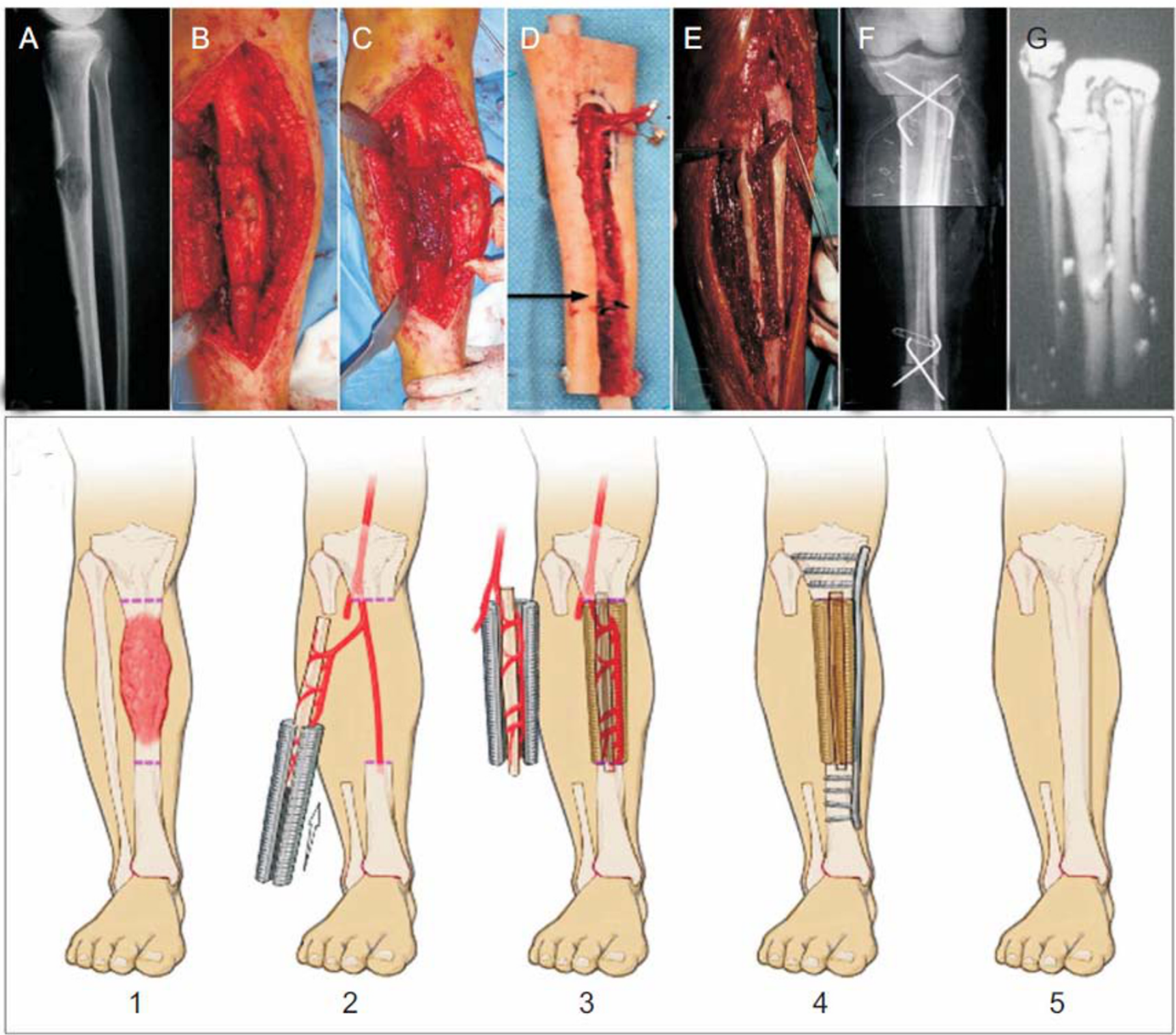

Figure 10 The vascularised fibula transfer is one of the most commonly used techniques for reconstruction of large tibial defects in orthopaedic oncology. The figure shows clinical case from a 16 year old girl with a malignant tumour of the mid-shaft of tibia. A: Xray showing destructive lesion. B: Segmental resection of tumour. C: Defect created by the removal of tumour. D: Example of reconstruction using vascularised fibular within allograft bone (Cappanna procedure). E: Reconstruction in-situ using vascularised fibular and allograft. F: postoperative X-ray images. G: 3D computed tomogram of reconstruction showing fibula enclosed by allograft bone material (Clinical case: P.F.C.). A novel biological approach to avoid the use of allograft material could be the combination of a vascularised fibula transfer with a custom made tissue engingeering construct as shown in H: After resection of the malignant tumour (1), a customized tubular scaffold is placed around the vascularised fibula autograft to fill the defect (2-3). Primary stability and even load distribution is achieved by using an internal fixation device (4). Secondary stability is achieved by osseointegration of both the fibula and the porous tissue engineering scaffold. Over time, the scaffold is slowly replaced by ingrowing tissue engineered bone and the defect is completely bridged and regenerated (5). H partly reproduced with permission from (246), @ The Authors. 
bone tissue engineering and the potential clinical applications as well as the difficulties in bridging the gap between research and clinical practice. Although the clinical translation of these approaches has not taken place on a large scale yet, bone tissue engineering clearly holds the potential to overcome historic limitations and disadvantages associated with the use of the current gold-standard autologous bone graft. Optimizing combinations of cells, scaffolds, and locally and systemic a lly a c tive stimuli will rema in a complex process characterized by a highly interdependent set of variables with a large range of possible variations. Consequently, these developments must also be nurtured and monitored by a combination of clinical experience, knowledge of basic biological principles, medical necessity, and commercial practic ality. The responsibility for rational development is shared by the entire orthopaedic community (developers, vendors, and physicians). The need for objective and systematic assessment and reporting is made particularly urgent by the recent rapid addition of many new options for clinical use. By applying a complex interplay of 21st century technologies from various disciplines of scientific research, the gap between bone tissue engineening research and the translation into clinically ava ilable bone tissue engineering applic ations can successfully be bridged.

\section{References}

1 Mason C. Regenerative medicine 2.0. Regen Med. 2007;2:11-18.

2 Webster TJ, Ahn ES. Nanostructured biomaterials for tissue engineering bone. Adv Biochem Eng Biotechnol. 2007;103:275308.

3 Rho JY, Kuhn-Spearing L, Zioupos P. Mechanical properties and the hierarchical structure of bone. Med Eng Phys. 1998;20:92-102.

4 Keaveny TM, Morgan EF, Niebur GL, Yeh OC. Biomechanics of trabecular bone. Annu Rev Biomed Eng. 2001;3:307-333.

5 Barrère F, Mahmood TA, de Groot K, van Blitterswijk CA. Advanced biomaterials for skeletal tissue regeneration: Instructive and smart functions. Mat Sci Eng R. 2008;59:38-71.

6 Kaplan FS, Keaveny TM, Boskey A, Einhorn TA, Iannotti JP. Form and function of bone. Am Acad Orthop Surg. 1994; 127-184.

7 Cooper DM, Matyas JR, Katzenberg MA, Hallgrimsson B. Comparison of microcomputed tomographic and microradiographic measurements of cortical bone porosity. Calcif Tissue Int. 2004;74:437-447.

8 Marks Jr SC. Structure and development of the skeleton. 2nd ed. Academic Press, 2002:3-15.

9 DiGirolamo DJ, Clemens TL, Kousteni S. The skeleton as an endocrine organ. Nat Rev Rheumatol. 2012;8:674-683.

10 Martin RB. Bone as a ceramic composite material. Mater Sci Forum. 1999;293:5-16.
11 Martin RB. Determinants of the mechanical properties of bones. J Biomech. 1991;24:79-88.

12 Kiebzak GM. Age-related bone changes. Exp Gerontol. 1991;26: 171-187.

13 Hench LL, Wilson J. An Introduction to Bioceramics. World Scientific, 1993.

14 Reilly DT, Burstein AH, Frankel VH. The elastic modulus for bone. J Biomech. 1974;7:271-275.

15 Choi K, Kuhn JL, Ciarelli MJ, Goldstein SA. The elastic moduli of human subchondral, trabecular, and cortical bone tissue and the size-dependency of cortical bone modulus. J Biomech. 1990;23: 1103-1113.

16 Rho JY, Tsui TY, Pharr GM. Elastic properties of human cortical and trabecular lamellar bone measured by nanoindentation. Biomaterials. 1997;18:1325-1330.

17 Jagodzinski M, Krettek C. Effect of mechanical stability on fracture healing--an update. Injury. 2007;38:S3-S10.

18 Pioletti DP. Biomechanics and tissue engineering. Osteoporos Int. 2011;22:2027-2031.

19 Klein-Nulend J, Bacabac RG, Mullender MG. Mechanobiology of bone tissue. Pathol Biol (Paris). 2005;53:576-580.

20 Epari DR, Taylor WR, Heller MO, Duda GN. Mechanical conditions in the initial phase of bone healing. Clin Biomech (Bristol, Avon). 2006;21:646-655.

21 Marsell R, Einhorn TA. The biology of fracture healing. Injury. 2011;42:551-555.

22 Dimitriou R, Jones E, McGonagle D, Giannoudis PV. Bone regeneration: current concepts and future directions. BMC Med. 2011;9:66.

23 Einhorn TA. Enhancement of fracture healing. Instr Course Lect. 1996;45:401-416.

24 Calori GM, Albisetti W, Agus A, Iori S, Tagliabue L. Risk factors contributing to fracture non-unions. Injury. 2007;38:S11- S18.

25 Sanan A, Haines SJ. Repairing holes in the head: a history of cranioplasty. Neurosurgery. 1997;40:588-603.

26 Courville C B. Cranioplasty in prehistoric times. Bull Los Ange Neuro Soc. 1959;24:1-8.

27 Flati G. Chirurgia nella preistoria. Parte I. Provincia Med Aquila. 2004;2:8-11.

28 Donati D, Zolezzi C, Tomba P, Viganò A. Bone grafting: historical and conceptual review, starting with an old manuscript by Vittorio Putti. Acta Orthop. 2007;78:19-25.

29 Haeseker B. Mr. Job van Meekeren (1611-1666) and surgery of the hand. Plast Reconstr Surg. 1988;82:539-546.

30 Meekeren JJ. Observationes Medico-Chirugicae. Amsterdam: Ex Officina Henrici \& Vidnae Theodori Boom. 1682.

31 Tarsoly E. [Filling of bone cavities with egg shell-plaster mixture] [Article in German] Acta Chir Acad Sci Hung. 1963;4:63-72.

32 Gluck T. Berl Klein Wochenschr. 1891;21:79.

33 Walter P. J Chir und Augen-Heilkunde. 1821;2:571.

34 MacEwen W. Observations concerning transplantation of bone illustrated by a case of inter-human osseous transplantation, 
whereby over two-thirds of the shaft of a humerus was restored. Proc Roy Soc Lond. 1881;32:232-247.

35 Ollier LL. Traite experimental et clinique de la regeneration des os et de la production artificielle du tissu osseux. V. Masson Vol. I and Vol. II. 1867.

36 Barth A. Histologische Untersuchung über Knochen implantationen. Beitr Pathol Anat Allg Pathol. 1895;17:65-142.

37 Bush LF. The use of homogenous bone grafts; a preliminary report on the bone bank. J Bone Joint Surg Am. 1947;29:620-628.

38 Chalmers J. Transplantation immunity in bone homografting. J Bone Joint Surg Br. 1959;41-B:160-179.

39 Enneking WF. Immunologic aspects of bone transplantation. South Med J. 1962;55:894-900

40 Maatz R. [The animal bone chip in the bone bank]. [Article in German] Dtsch Med J. 1957;8:190-194.

41 Katthagen BD. Knochenregeneration mit Knochenersatzmaterialien: Eine tierexperimentelle studie. Hefte Unfallheilk. 1986.

42 Hinsenkamp M, Muylle L, Eastlund T, Fehily D, Noël L, Strong DM. Adverse reactions and events related to musculoskeletal allografts: reviewed by the World Health Organisation Project NOTIFY. Int Orthop. 2012;36:633-641.

43 Matti H. Ueber die freie Transplantation von Knochenspongiosa. Langenbecks Arch Clin Chir. 1932:168-236.

44 Schweiberer L. [Experimental studies on bone transplantation with unchanged and denaturated bone substance. A contribution on causal osteogenesis]. [Article in German]. Hefte Unfallheilkd. 1970;103:1-70.

45 Dinopoulos H, Dimitriou R, Giannoudis PV. Bone graft substitutes: What are the options? Surgeon. 2012;10:230-239.

46 De Long WG Jr, Einhorn TA, Koval K, McKee M, Smith W, Sanders R, Watson T. Bone grafts and bone graft substitutes in orthopaedic trauma surgery. A critical analysis. J Bone Joint Surg Am. 2007;89:649-658.

47 Schieker M, Heiss C, Mutschler W. [Bone substitutes]. [Article in German]. Unfallchirurg. 2008;111:613-619; quiz 620.

48 Myeroff C, Archdeacon M. Autogenous bone graft: donor sites and techniques. J Bone Joint Surg Am. 2011;93:2227-2236.

49 Stafford PR, Norris BL. Reamer-irrigator-aspirator bone graft and bi Masquelet technique for segmental bone defect nonunions: a review of 25 cases. Injury. 2010;41:S72-S77.

50 Weiland AJ, Phillips TW, Randolph MA. Bone grafts: a radiologic, histologic, and biomechanical model comparing autografts, allografts, and free vascularized bone grafts. Plast Reconstr Surg. 1984;74:368-379.

51 Pederson WC, Person DW. Long bone reconstruction with vascularized bone grafts. Orthop Clin North Am. 2007;38:23-35.

52 Aronson J. Limb-lengthening, skeletal reconstruction, and bone transport with the Ilizarov method. J Bone Joint Surg Am. 1997; 79:1243-1258

53 Sailhan F. Bone lengthening (distraction osteogenesis): a literature review. Osteoporos Int. 2011;22:2011-2015.

54 Spiegelberg B, Parratt T, Dheerendra SK, Khan WS, Jennings R,
Marsh DR. Ilizarov principles of deformity correction. Ann R Coll Surg Engl. 2010;92:101-105.

55 Paley D, Maar DC. Ilizarov bone transport treatment for tibial defects. J Orthop Trauma. 2000;14:76-85.

56 Dendrinos GK, Kontos S, Lyritsis E. Use of the Ilizarov technique for treatment of non-union of the tibia associated with infection. J Bone Joint Surg Am. 1995;77:835-846.

57 Smith JO, Aarvold A, Tayton ER, Dunlop DG, Oreffo RO. Skeletal tissue regeneration: current approaches, challenges, and novel reconstructive strategies for an aging population. Tissue Eng Part B Rev. 2011;17:307-320.

58 Klaue K, Knothe U, Masquelet A. Effet biologique des membranes à corps etranger induites in situ sur la consolidation des greffes d'os spongieux. Rev Chir Orthop Suppl. 1995;70:109-110.

59 Giannoudis PV, Faour O, Goff T, Kanakaris N, Dimitriou R. Masquelet technique for the treatment of bone defects: tips-tricks and future directions. Injury. 2011;42:591-598.

60 Masquelet AC, Begue T. The concept of induced membrane for reconstruction of long bone defects. Orthop Clin North Am. 2010; 41:27-37.

61 Pelissier P, Masquelet AC, Bareille R, Pelissier SM, Amedee J. Induced membranes secrete growth factors including vascular and osteoinductive factors and could stimulate bone regeneration. J Orthop Res. 2004;22:73-79.

62 Pélissier P, Lefevre Y, Delmond S, Villars F, Vilamitjana-Amedee J [Influences of induced membranes on heterotopic bone formation within an osteo-inductive complex. Experimental study in rabbits]. [Article in French]. Ann Chir Plast Esthet. 2009;54:16-20.

63 DepuySynthes. Reamer/Irrigator/Aspirator (RIA). <http:// www.synthes.com/sites/NA/Products/Trauma/Intramedullary NailingSystems/Pages/Reamer_Irrigator_Aspirator_RIA.aspx>. 2013.

64 McCall TA, Brokaw DS, Jelen BA, Scheid DK, Scharfenberger AV, Maar DC, Green JM, Shipps MR, Stone MB, Musapatika D, Weber TG. Treatment of large segmental bone defects with reamerirrigator-aspirator bone graft: technique and case series. Orthop Clin North Am. 2010;4163-4173.

65 Husebye EE, Lyberg T, Madsen JE, Eriksen M, Røise O. The influence of a one-step reamer-irrigator-aspirator technique on the intramedullary pressure in the pig femur. Injury. 2006;37: 935-940.

66 Belthur MV, Conway JD, Jindal G, Ranade A, Herzenberg JE Bone graft harvest using a new intramedullary system. Clin Orthop Relat Res. 2008;466:2973-2980.

67 Newman JT, Stahel PF, Smith WR, Resende GV, Hak DJ, Morgan SJ. A new minimally invasive technique for large volume bone graft harvest for treatment of fracture nonunions. Orthopedics. 2008;31:257-261.

68 Dimitriou R, Mataliotakis GI, Angoules AG, Kanakaris NK, Giannoudis PV. Complications following autologous bone graft harvesting from the iliac crest and using the RIA: a systematic review. Injury. 2011;42:S3-S15. 
69 Zalavras CG, Singh A, Patzakis MJ. Novel technique for medullary canal débridement in tibia and femur osteomyelitis. Clin Orthop Relat Res. 2007;461:31-34.

70 Porter RM, Liu F, Pilapil C, Betz OB, Vrahas MS, Harris MB, Evans $\mathrm{CH}$. Osteogenic potential of reamer irrigator aspirator (RIA) aspirate collected from patients undergoing hip arthroplasty. J Orthop Res. 2009;27:42-49.

71 Kanakaris NK, Morell D, Gudipati S, Britten S, Giannoudis PV. Reaming Irrigator Aspirator system: early experience of its multipurpose use. Injury. 2011;42:S28-S34.

72 Cox G, Jones E, McGonagle D, Giannoudis PV. Reamer-irrigatoraspirator indications and clinical results: a systematic review. Int Orthop. 2011;35:951-956.

73 Huffman LK, Harris JG, Suk M. Using the bi-masquelet technique and reamer-irrigator-aspirator for post-traumatic foot reconstruction. Foot Ankle Int. 2009;30:895-899.

74 Schlickewei W, Schlickewei C. The Use of Bone Substitutes in the Treatment of Bone Defects-the Clinical View and History. Macromol Symp. 2007;253:10-23.

75 Langer R, Vacanti JP. Tissue engineering. Science. 1993;260:920926.

76 Kolk A, Handschel J, Drescher W, Rothamel D, Kloss F, Blessmann M, Heiland M, Wolff KD, Smeets R. Current trends and future perspectives of bone substitute materials - from space holders to innovative biomaterials. J Craniomaxillofac Surg. 2012; 40:706-718.

77 Giannoudis PV, Einhorn TA, Marsh D. Fracture healing: the diamond concept. Injury. 2007;38:S3-S6.

78 Giannoudis PV, Einhorn TA, Schmidmaier G, Marsh D. The diamond concept--open questions. Injury. 2008;39:S5-S8.

79 Hutmacher DW, Schantz JT, Lam CX, Tan KC, Lim TC. State of the art and future directions of scaffold-based bone engineering from a biomaterials perspective. J Tissue Eng Regen Med. 2007;1: 245-260.

80 Woodruff MA, Lange C, Reichert J, Berner A, Chen F, Fratzl P, Schantz JT, Hutmacher DW. Bone tissue engineering: from bench to bedside. Materials Today. 2012;15:430-434.

81 Laurencin C, Khan Y, El-Amin SF. Bone graft substitutes. Expert Rev Med Devices. 2006;3:49-57.

82 Dinopoulos HT, Giannoudis PV. Safety and efficacy of use of demineralised bone matrix in orthopaedic and trauma surgery. Expert Opin Drug Saf. 2006;5:847-866.

83 Katz JM, Nataraj C, Jaw R, Deigl E, Bursac P. Demineralized bone matrix as an osteoinductive biomaterial and in vitro predictors of its biological potential. J Biomed Mater Res B Appl Biomater. 2009;89:127-134.

84 Bostrom MP, Seigerman DA. The clinical use of allografts, demineralized bone matrices, synthetic bone graft substitutes and osteoinductive growth factors: a survey study. HSS J. 2005;1:9-18.

85 Tadic D, Epple M. A thorough physicochemical characterisation of 14 calcium phosphate-based bone substitution materials in comparison to natural bone. Biomaterials. 2004;25:987-994.
86 Damien E, Revell PA. Coralline hydroxyapatite bone graft substitute: A review of experimental studies and biomedical applications. J Appl Biomater Biomech. 2004;2:65-73.

87 Ewers R. Maxilla sinus grafting with marine algae derived bone forming material: a clinical report of long-term results. J Oral Maxillofac Surg. 2005;63:1712-1723.

88 Baino F, Vitale-Brovarone C. Three-dimensional glass-derived scaffolds for bone tissue engineering: current trends and forecasts for the future. J Biomed Mater Res A. 2011;97:514-535.

89 Hammouche S, Khan W, Drouin H, Procter H, McNicholas M. Calcium salts bone regeneration scaffolds: a review article. Curr Stem Cell Res Ther. 2012;7:336-346.

90 Liu B, Lun DX. Current application of beta-tricalcium phosphate composites in orthopaedics. Orthop Surg. 2012;4:139-144.

91 Sun F, Zhou H, Lee J. Various preparation methods of highly porous hydroxyapatite/polymer nanoscale biocomposites for bone regeneration. Acta Biomater. 2011;7:3813-3828.

92 Hutmacher DW, Cool S. Concepts of scaffold-based tissue engineering--the rationale to use solid free-form fabrication techniques. J Cell Mol Med. 2007;11: 654-669.

93 Swetha M, Sahithi K, Moorthi A, Srinivasan N, Ramasamy K, Selvamurugan N. Biocomposites containing natural polymers and hydroxyapatite for bone tissue engineering. Int $\mathrm{J}$ Biol Macromol. 2010;47:1-4.

94 Bose S, Tarafder S. Calcium phosphate ceramic systems in growth factor and drug delivery for bone tissue engineering: a review. Acta Biomater. 2012; 8:1401-1421.

95 Woodruff MA, Hutmacher DW. The return of a forgotten polymer-Polycaprolactone in the 21st century. Prog Polym Sci. 2010;35:1217-1256

96 Puppi D, Chiellini F, Piras AM, Chiellini E. Polymeric materials for bone and cartilage repair. Prog Polym Sci. 2010;35:403-440.

97 Hutmacher DW. Scaffolds in tissue engineering bone and cartilage. Biomaterials. 2000;21:2529-2543.

98 Tanner KE. Bioactive composites for bone tissue engineering Proc Inst Mech Eng H. 2010;224:1359-1372.

99 Miyazaki T. Design of bone-integrating organic-inorganic composite suitable for bone repair. Front Biosci (Elite Ed). 2013;5:333340.

100 Dimitriou R, Tsiridis E, Giannoudis PV. Current concepts of molecular aspects of bone healing. Injury. 2005;36:1392-1404.

101 Salgado AJ, Coutinho OP, Reis RL. Bone tissue engineering: state of the art and future trends. Macromol Biosci. 2004;4:743-765.

102 Reichert JC, Cipitria A, Epari DR, Saifzadeh S, Krishnakanth P, Berner A, Woodruff MA, Schell H, Mehta M, Schuetz MA, Duda GN, Hutmacher DW. A tissue engineering solution for segmental defect regeneration in load-bearing long bones. Sci Transl Med. 2012;4:141ra93.

103 Chatterjea A, Meijer G, van Blitterswijk C, de Boer J. Clinical application of human mesenchymal stromal cells for bone tissue engineering. Stem Cells Int. 2010;2010:215625.

104 Baksh D, Song L, Tuan RS. Adult mesenchymal stem cells: 
characterization, differentiation, and application in cell and gene therapy. J Cell Mol Med. 2004;8:301-316.

105 Hui JH, Ouyang HW, Hutmacher DW, Goh JC, Lee EH. Mesenchymal stem cells in musculoskeletal tissue engineering: a review of recent advances in National University of Singapore. Ann Acad Med Singapore. 2005;34:206-212.

106 Xiao Y, Mareddy S, Crawford R. Clonal characterization of bone marrow derived stem cells and their application for bone regeneration. Int J Oral Sci. 2010;2:127-135.

107 Kagami H, Agata H, Tojo A. Bone marrow stromal cells (bone marrow-derived multipotent mesenchymal stromal cells) for bone tissue engineering: basic science to clinical translation. Int J Biochem Cell Biol. 2011;43:286-289.

108 Colnot C, Zhang X, Knothe Tate ML. Current insights on the regenerative potential of the periosteum: molecular, cellular, and endogenous engineering approaches. J Orthop Res. 2012;30:18691878 .

109 Hutmacher DW, Sittinger M. Periosteal cells in bone tissue engineering. Tissue Eng. 2003;9:S45-S64.

110 Jayakumar P, Di Silvio L. Osteoblasts in bone tissue engineering. Proc Inst Mech Eng H. 2010;224:1415-1440.

111 Longo UG, Loppini M, Berton A, La Verde L, Khan WS, Denaro V. Stem cells from umbilical cord and placenta for musculoskeletal tissue engineering. Curr Stem Cell Res Ther. 2012;7:272-281.

112 Mizuno H. Adipose-derived stem cells for tissue repair and regeneration: ten years of research and a literature review. J Nippon Med Sch. 2009;76:56-66.

113 Amini AR, Laurencin CT, Nukavarapu SP. Bone tissue engineering: recent advances and challenges. Crit Rev Biomed Eng. 2012;40:363-408.

114 Szpalski C, Barbaro M, Sagebin F, Warren SM. Bone tissue engineering: current strategies and techniques--part II: Cell types. Tissue Eng Part B Rev. 2012;18:258-269.

115 Colnot $C$. Cell sources for bone tissue engineering: insights from basic science. Tissue Eng Part B Rev. 2011;17:449-457.

116 Mason C, Dunnill P. Assessing the value of autologous and allogeneic cells for regenerative medicine. Regen Med. 2009;4:835853.

117 Nandi SK, Roy S, Mukherjee P, Kundu B, De DK, Basu D. Orthopaedic applications of bone graft \& graft substitutes: a review. Indian J Med Res. 2010;132:15-30.

118 Groeneveld EH, van den Bergh JP, Holzmann P, ten Bruggenkate $\mathrm{CM}$, Tuinzing DB, Burger EH. Mineralization processes in demineralized bone matrix grafts in human maxillary sinus floor elevations. J Biomed Mater Res. 1999;48:393-402.

119 Stark GB, Horch R, Tanczos E. Biological Matrices and Tissue Reconstruction. Springer, Berlin. 1998:197-206.

120 Bostman O, Hirvensalo E, Makinen J, Rokkanen P. Foreign-body reactions to fracture fixation implants of biodegradable synthetic polymers. J Bone Joint Surg Br. 1990;72:592-596.

121 Bergsma EJ, Rozema FR, Bos RR, de Bruijn WC. Foreign body reactions to resorbable poly(L-lactide) bone plates and screws used for the fixation of unstable zygomatic fractures. J Oral Maxillofac Surg. 1993;51:666-670.

122 Bergsma JE, de Bruijn WC, Rozema FR, Bos RR, Boering G. Late degradation tissue response to poly(L-lactide) bone plates and screws. Biomaterials. 1995;16:25-31.

123 Velard F, Braux J, Amedee J, Laquerriere P. Inflammatory cell response to calcium phosphate biomaterial particles: an overview Acta Biomater. 2013;9:4956-4963.

124 Hollinger JO, Chaudhari A. Bone regeneration materials for the mandibular and craniofacial complex. Cells Mater. 1992;2:143151.

125 Babis GC, Soucacos PN. Bone scaffolds: the role of mechanical stability and instrumentation. Injury. 2005;36 Suppl 4:S38-S44.

126 Ponche A, Bigerelle M, Anselme K. Relative influence of surface topography and surface chemistry on cell response to bone implant materials. Part 1: physico-chemical effects. Proc Inst Mech Eng H. 2010;224:1471-1486.

127 Boyan BD, Hummert TW, Dean DD, Schwartz Z. Role of material surfaces in regulating bone and cartilage cell response. Biomaterials. 1996;17:137-146.

128 Kaplan FS, Hayes WC, Keaveny TM, Boskey A, Einhorn TA, Iannotti JP. Formation and Function of Bone. In: Simon SR, editor. Orthopedic Basic Science. American Academy of Orthopedic Surgeons; Rosemont, Illinois: 1994:127-184.

129 Webster TJ, Ergun C, Doremus RH, Siegel RW, Bizios R. Specific proteins mediate enhanced osteoblast adhesion on nanophase ceramics. J Biomed Mater Res. 2000;51:475-483.

130 Webster TJ, Schadler LS, Siegel RW, Bizios R. Mechanisms of enhanced osteoblast adhesion on nanophase alumina involve vitronectin. Tissue Eng. 2001;7:291-301.

131 Webster TJ, Siegel RW, Bizios R. Osteoblast adhesion on nanophase ceramics. Biomaterials. 1999;20:1221-1227.

132 Puckett S, Pareta R, Webster TJ. Nano rough micron patterned titanium for directing osteoblast morphology and adhesion. Int J Nanomedicine. 2008;3:229-241.

133 Vlacic-Zischke J, Hamlet SM, Friis T, Tonetti MS, Ivanovski S. The influence of surface microroughness and hydrophilicity of titanium on the up-regulation of TGFbeta/BMP signalling in osteoblasts. Biomaterials. 2011;32:665-671.

134 Chan O, Coathup MJ, Nesbitt A, Ho CY, Hing KA, Buckland T, Campion C, Blunn GW. The effects of microporosity on osteoinduction of calcium phosphate bone graft substitute biomaterials. Acta Biomater. 2012;8:2788-2794.

135 Scott TG, Blackburn G, Ashley M, Bayer IS, Ghosh A, Biris AS, Biswas A. Advances in bionanomaterials for bone tissue engineering. J Nanosci Nanotechnol. 2013;13:1-22.

136 McMahon RE, Wang L, Skoracki R, Mathur AB. Development of nanomaterials for bone repair and regeneration. J Biomed Mater Res B Appl Biomater. 2013;101:387-397.

137 Egli RJ, Luginbuehl R. Tissue engineering - nanomaterials in the musculoskeletal system. Swiss Med Wkly. 2012;142:w13647.

138 Saiz E, Zimmermann EA, Lee JS, Wegst UG, Tomsia AP. 
Perspectives on the role of nanotechnology in bone tissue engineering. Dent Mater. 2013;29:103-115.

Yuan H, Kurashina K, de Bruijn JD, Li Y, de Groot K, Zhang X. A preliminary study on osteoinduction of two kinds of calcium phosphate ceramics. Biomaterials. 1999;20:1799-1806.

140 Davies JE. In vitro modeling of the bone/implant interface. Anat Rec. 1996;245:426-445.

141 Albrektsson T, Johansson C. Osteoinduction, osteoconduction and osseointegration. Eur Spine J. 2001;10 Suppl 2:S96-S101.

142 Habibovic P, de Groot K. Osteoinductive biomaterials--properties and relevance in bone repair. J Tissue Eng Regen Med. 2007;1:25-32.

143 Geesink RG, de Groot K, Klein CP. Bonding of bone to apatite-coated implants. J Bone Joint Surg Br. 1993;70:17-22.

144 Kay JF. Biological profile of calcium phosphate coatings. 1993: 89-106.

145 Hanawa T, Kamiura Y, Yamamoto S, Kohgo T, Amemiya A, Ukai H, Murakami K, Asaoka K. Early bone formation around calcium-ion-implanted titanium inserted into rat tibia. J Biomed Mater Res. 1997;36:131-136.

146 Le Huec JC, Clément D, Brouillaud B, Barthe N, Dupuy B, Foliguet B, Basse-Cathalinat B. Evolution of the local calcium content around irradiated beta-tricalcium phosphate ceramic implants: in vivo study in the rabbit. Biomaterials. 1998;19:733738.

147 LeGeros RZ. Calcium phosphate-based osteoinductive materials. Chem Rev. 2008;108:4742-4753.

148 Vaquette C, Ivanovski S, Hamlet SM, Hutmacher DW. Effect of culture conditions and calcium phosphate coating on ectopic bone formation. Biomaterials. 2013;34:5538-5551.

149 Habibovic P, Sees TM, van den Doel MA, van Blitterswijk CA, de Groot K. Osteoinduction by biomaterials--physicochemical and structural influences. J Biomed Mater Res A. 2006;77:747-762.

150 Barradas AM, Yuan H, van Blitterswijk CA, Habibovic P. Osteoinductive biomaterials: current knowledge of properties, experimental models and biological mechanisms. Eur Cell Mater. 2011;21:407-429.

151 Yuan H, De Bruijn JD, Li Y, Feng J, Yang Z, De Groot K, Zhang X. Bone formation induced by calcium phosphate ceramics in soft tissue of dogs: a comparative study between porous alpha-TCP and beta-TCP. J Mater Sci Mater Med. 2001;12:7-13.

152 Chai YC, Carlier A, Bolander J, Roberts SJ, Geris L, Schrooten J, Van Oosterwyck H, Luyten FP. Current views on calcium phosphate osteogenicity and the translation into effective bone regeneration strategies. Acta Biomater. 2012;8:3876-3887.

153 Anselme K, Ponche A, Bigerelle M. Relative influence of surface topography and surface chemistry on cell response to bone implant materials. Part 2: biological aspects. Proc Inst Mech Eng H. 2010;224:1487-1507.

154 Leon CLY. New perspectives in mercury porosimetry. Adv Colloid Interface Sci. 1998;76:341-372.

155 Kuboki Y, Takita H, Kobayashi D, Tsuruga E, Inoue M, Murata M,
Nagai N, Dohi Y, Ohgushi H. BMP-induced osteogenesis on the surface of hydroxyapatite with geometrically feasible and nonfeasible structures: topology of osteogenesis. J Biomed Mater Res. 1998;39:190-199.

156 Story BJ, Wagner WR, Gaisser DM, Cook SD, Rust-Dawicki AM In vivo performance of a modified CSTi dental implant coating. Int J Oral Maxillofac Implants. 1998;13:749-757.

157 Karageorgiou V, Kaplan D. Porosity of 3D biomaterial scaffolds and osteogenesis. Biomaterials. 2005;26:5474-5491.

158 Hulbert SF, Young FA, Mathews RS, Klawitter JJ, Talbert CD, Stelling FH. Potential of ceramic materials as permanently implantable skeletal prostheses. J Biomed Mater Res. 1970;4:433456.

159 Loh QL, Choong C. Three-dimensional scaffolds for tissue engineering: role of porosity and pore size. Tissue Eng Part B Rev. 2013 May 14. [Epub ahead of print].

160 Szpalski C, Wetterau M, Barr J, Warren SM. Bone tissue engineering: current strategies and techniques--part I: Scaffolds. Tissue Eng Part B Rev. 2012;18:246-257.

161 Bose S, Roy M, Bandyopadhyay A. Recent advances in bone tissue engineering scaffolds. Trends Biotechnol. 2012;30:546-554.

162 Peltola SM, Melchels FP, Grijpma DW, Kellomaki M. A review of rapid prototyping techniques for tissue engineering purposes. Ann Med. 2008;40:268-280.

163 Hutmacher DW, Sittinger M, Risbud MV. Scaffold-based tissue engineering: rationale for computer-aided design and solid free-form fabrication systems. Trends Biotechnol. 2004;22:354-362.

164 Yeong WY, Chua CK, Leong KF, Chandrasekaran M. Rapid prototyping in tissue engineering: challenges and potential. Trends Biotechnol. 2004;22:643-652.

165 Sachlos E, Czernuszka JT. Making tissue engineering scaffolds work. Review: the application of solid freeform fabrication technology to the production of tissue engineering scaffolds. Eur Cell Mater. 2003;5:29-39; discussion 39-40.

166 Melchels FPW, Domingos MAN, Klein TJ, Malda J, Bartolo PJ, Hutmacher DW. Additive manufacturing of tissues and organs. Prog Polym Sci. 2012;37:1079-1104.

167 ASTM Standard F2792-10: Standard terminology for additive manufacturing technologies. ASTM International, 2010.

168 Ballyns JJ, Bonassar LJ. Image-guided tissue engineering. J Cell Mol Med. 2009;13:1428-1436.

169 Hollister SJ. Porous scaffold design for tissue engineering. Nat Mater. 2005;4:518-524.

170 Derby B. Printing and prototyping of tissues and scaffolds. Science. 2012;338:921-926.

171 Wendel B, Rietzel D, Kühnlein F, Feulner R, Hülder G, Schmachtenberg E. Additive Processing of Polymers. Macromol Mater Eng. 2008;293:799-809.

172 Webb PA. A review of rapid prototyping (RP) techniques in the medical and biomedical sector. J Med Eng Technol. 2000;24:149153.

173 McGurk M, Amis AA, Potamianos P, Goodger NM. Rapid 
prototyping techniques for anatomical modelling in medicine. Ann R Coll Surg Engl. 1997;79:169-174.

174 Potamianos P, Amis AA, Forester AJ, McGurk M, Bircher M. Rapid prototyping for orthopaedic surgery. Proc Inst Mech Eng $\mathrm{H}$. 1998;212:383-393.

175 Goiato MC, Santos MR, Pesqueira AA, Moreno A, dos Santos DM, Haddad MF. Prototyping for surgical and prosthetic treatment. J Craniofac Surg. 2011;22:914-917.

176 Debarre E, Hivart P, Baranski D, Déprez P. Speedy skeletal prototype production to help diagnosis in orthopaedic and trauma surgery. Methodology and examples of clinical applications. Orthop Traumatol Surg Res. 2012;98:597-602.

177 Esses SJ, Berman P, Bloom AI, Sosna J. Clinical applications of physical 3D models derived from MDCT data and created by rapid prototyping. AJR Am J Roentgenol. 2011;196:W683-W688.

178 Melchels FP, Feijen J, Grijpma DW. A review on stereolithography and its applications in biomedical engineering. Biomaterials. 2010;31:6121-6130.

179 Maruo S, Ikuta K. Submicron stereolithography for the production of freely movable mechanisms by using single-photon polymerization. Sensor Actuat A: Phys. 2002;100:70-76

180 Chehade MJ, Bachorski A. Development of the Australian core competencies in musculoskeletal basic and clinical science project - phase 1. Med J Aust. 2008;189:162-165.

181 Siegel R, Naishadham D, Jemal A. Cancer statistics, 2012. CA Cancer J Clin. 2012;62:10-29.

182 Lysaght MJ, Reyes J. The growth of tissue engineering. Tissue Eng. 2001;7:485-493.

183 Wang FS. Support for tissue engineering and regenerative medicine by the National Institutes of Health. Artech House Publishers. 2008:445-462.

184 Hollister SJ. Scaffold engineering: a bridge to where? Biofabrication. 2009;1:012001

185 Reichert JC, Epari DR, Wullschleger ME, Saifzadeh S, Steck R, Lienau J, Sommerville S, Dickinson IC, Schütz MA, Duda GN, Hutmacher DW. Establishment of a preclinical ovine model for tibial segmental bone defect repair by applying bone tissue engineering strategies. Tissue Eng Part B Rev. 2010;16:93-104.

186 Meslin EM, Blasimme A, Cambon-Thomsen A. Mapping the translational science policy 'valley of death'. Clin Transl Med. 2013;2:14.

187 Dawson JI, Oreffo RO. Bridging the regeneration gap: stem cells, biomaterials and clinical translation in bone tissue engineering. Arch Biochem Biophys. 2008;473:124-131.

188 Yannas IV. Emerging rules for inducing organ regeneration. Biomaterials. 2013;34:321-330

189 Hollister SJ, Murphy WL. Scaffold translation: barriers between concept and clinic. Tissue Eng Part B Rev. 2011;17:459-474.

190 Kneser U, Schaefer DJ, Polykandriotis E, Horch RE. Tissue engineering of bone: the reconstructive surgeon's point of view. J Cell Mol Med. 2006;10:7-19.

191 Logeart-Avramoglou D, Anagnostou F, Bizios R, Petite H.
Engineering bone: challenges and obstacles. J Cell Mol Med. 2005;9:72-84

192 Muschler GF, Raut VP, Patterson TE, Wenke JC, Hollinger JO. The design and use of animal models for translational research in bone tissue engineering and regenerative medicine. Tissue Eng Part B Rev. 2010;16:123-145.

193 Schoonen WG, Westerink WM, Horbach GJ. High-throughput screening for analysis of in vitro toxicity. EXS. 2009;99:401-452.

194 Colas P. High-throughput screening assays to discover smallmolecule inhibitors of protein interactions. Curr Drug Discov Technol. 2008;5:190-199.

195 Horner EA, Kirkham J, Wood D, Curran S, Smith M, Thomson B, Yang $\mathrm{XB}$. Long bone defect models for tissue engineering applications: criteria for choice. Tissue Eng Part B Rev. 2010;16:263-271.

196 Mooney MP, Siegel MI. Animal models for bone tissue engineering. In: Wnek, G. and Bowlin, G. (Eds.). Encyclopedia of Biomaterials and Biomedical Engineering. Marcel Dekker, New York, 2005:1-19.

197 Buma P, Schreurs W, Verdonschot N. Skeletal tissue engineeringfrom in vitro studies to large animal models. Biomaterials. 2004;25 1487-1495.

198 Einhorn TA. Clinically applied models of bone regeneration in tissue engineering research. Clin Orthop Relat Res. 1999;367: S59-S67.

199 O'Loughlin PF, Morr S, Bogunovic L, Kim AD, Park B, Lane JM. Selection and development of preclinical models in fracture-healing research. J Bone Joint Surg Am. 2008;90:79-84.

200 Woodruff MA, Hutmacher DW. The return of a forgotten polymer: Polycaprolactone in the 21st century. Prog Polym Sci. 2010;35:1217-1256.

201 Zein I, Hutmacher DW, Tan KC, Teoh SH. Fused deposition modeling of novel scaffold architectures for tissue engineering applications. Biomaterials. 2002;23:1169-1185.

202 Sawyer AA, Song SJ, Susanto E, Chuan P, Lam CX, Woodruff MA, Hutmacher DW, Cool SM. The stimulation of healing within a rat calvarial defect by mPCL-TCP/collagen scaffolds loaded with rhBMP-2. Biomaterials. 2009;30:2479-2488

203 Lam CX, Teoh SH, Hutmacher DW. Comparison of the degradation of polycaprolactone and polycaprolactone- $(\beta$ tricalcium phosphate) scaffolds in alkaline medium. Polym Int. 2007;56:718-728

204 Lam CX, Hutmacher DW, Schantz JT, Woodruff MA, Teoh SH. Evaluation of polycaprolactone scaffold degradation for 6 months in vitro and in vivo. J Biomed Mater Res A. 2009;90:906-919.

205 Lam CX, Savalani MM, Teoh SH, Hutmacher DW. Dynamics of in vitro polymer degradation of polycaprolactone-based scaffolds: accelerated versus simulated physiological conditions. Biomed Mater. 2008;3:034108.

206 Ekaputra AK, Zhou Y, Cool SM, Hutmacher DW. Composite electrospun scaffolds for engineering tubular bone grafts. Tissue Eng Part A. 2009;15:3779-3788.

207 Berner A, Boerckel JD, Saifzadeh S, Steck R, Ren J, Vaquette C, 
Zhang JQ, Nerlich M, Guldberg RE, Hutmacher DW, Woodruff MA. Biomimetic tubular nanofiber mesh and platelet rich plasma-mediated delivery of BMP-7 for large bone defect regeneration. Cell Tissue Res. 2012;347:603-612.

Rai B, Lin JL, Lim ZX, Guldberg RE, Hutmacher DW, Cool SM. Differences between in vitro viability and differentiation and in vivo bone-forming efficacy of human mesenchymal stem cells cultured on PCL-TCP scaffolds. Biomaterials. 2010;31:7960-7970. DW.Combined marrow stromal cell-sheet techniques and high-strength biodegradable composite scaffolds for engineered functional bone grafts. Biomaterials. 2007;28:814-824.

210 Berner A, Reichert JC, Müller MB, Zellner J, Pfeifer C, Dienstknecht T, Nerlich M, Sommerville S, Dickinson IC, Schütz MA, Füchtmeier B. Treatment of long bone defects and non-unions: from research to clinical practice. Cell Tissue Res. 2012;347:501-519.

211 Reichert JC, Saifzadeh S, Wullschleger ME, Epari DR, Schütz MA, Duda GN, Schell H, van Griensven M, Redl H, Hutmacher DW. The challenge of establishing preclinical models for segmental bone defect research. Biomaterials. 2009;30:2149-2163.

212 Reichert JC, Wullschleger ME, Cipitria A, Lienau J, Cheng TK, Schütz MA, Duda GN, N?th U, Eulert J, Hutmacher DW. Custom-made composite scaffolds for segmental defect repair in long bones. Int Orthop. 2011;35:1229-1236.

213 Reichert JC, Cipitria A, Epari DR, Saifzadeh S, Krishnakanth P, Berner A, Woodruff MA, Schell H, Mehta M, Schuetz MA, Duda GN, Hutmacher DW. A Tissue Engineering Solution for Segmental Defect Regeneration in Long Bones. Sci Transl Med. 2012;4:141ra93.

214 Reichert JC, Epari DR, Wullschleger ME, Saifzadeh S, Steck R, Lienau J, Sommerville S, Dickinson IC, Schütz MA, Duda GN, Hutmacher DW. Establishment of a preclinical ovine model for tibial segmental bone defect repair by applying bone tissue engineering strategies. Tissue Eng Part B Rev. 2010;16:93-104.

215 Berner A, Reichert JC, Woodruff MA, Saifzadeh S, Morris AJ, Epari DR, Nerlich M, Schuetz MA, Hutmacher DW. Autologous vs. allogenic mesenchymal progenitor cells for the reconstruction of critical sized segmental tibial bone defects in aged sheep. Acta Biomater. 2013;9:7874-7884

216 Tzioupis C, Giannoudis PV. Prevalence of long-bone non-unions. Injury. 2007;38:S3-S9.

217 Court-Brown CM, Caesar B. Epidemiology of adult fractures: A review. Injury. 2006;37:691-697.

218 Audigé L, Griffin D, Bhandari M, Kellam J, Rüedi TP. Path analysis of factors for delayed healing and nonunion in 416 operatively treated tibial shaft fractures. Clin Orthop Relat Res. 2005;438:221232.

219 Sandhu HS, Khan SN. Animal models for preclinical assessment of bone morphogenetic proteins in the spine. Spine (Phila Pa 1976). 2002;27:S32-S38.

220 Drespe, I. H., Polzhofer, G. K., Turner, A. S. \& Grauer, J. N. Animal models for spinal fusion. Spine J. 2005;5:209S-216S.

221 Hecht BP, Fischgrund JS, Herkowitz HN, Penman L, Toth JM,
Shirkhoda A. The use of recombinant human bone morphogenetic protein 2 (rhBMP-2) to promote spinal fusion in a nonhuman primate anterior interbody fusion model. Spine (Phila Pa 1976). 1999;24:629-636.

222 Cunningham BW, Kanayama M, Parker LM, Weis JC, Sefter JC, Fedder IL, McAfee PC. Osteogenic protein versus autologous interbody arthrodesis in the sheep thoracic spine. A comparative endoscopic study using the Bagby and Kuslich interbody fusion device. Spine (Phila Pa 1976). 1999;24:509-518

223 Oehme D, Goldschlager T, Rosenfeld J, Danks A, Ghosh P, Gibbon A, Jenkin G.Lateral surgical approach to lumbar intervertebral discs in an ovine model. Sci World J. 2012;2012:873726.

224 Dubousset J. Scoliosis and its pathophysiology: do we understand it? Spine (Phila Pa 1976). 2001;26:1001.

225 Danielsson AJ, Nachemson AL. Back pain and function 22 years after brace treatment for adolescent idiopathic scoliosis: a casecontrol study-part I. Spine (Phila Pa 1976). 2003;28:2078-2085; discussion 2086.

226 Reid JJ, Johnson JS, Wang JC. Challenges to bone formation in spinal fusion. J Biomech. 2011;44:213-220.

227 Whang PG, Wang JC. Bone graft substitutes for spinal fusion. Spine J. 2003;3:155-165.

228 Miyazaki M, Tsumura H, Wang JC, Alanay A. An update on bone substitutes for spinal fusion. Eur Spine J. 2009;18:783-799.

229 Mroz TE, Suen PW, Shamie AN, Whang PG, Wang JC. Bone graft substitutes in spinal surgery. Oper Tech Orthop. 2003;13:146-151.

230 Khan SN, Lane JM. Spinal fusion surgery: animal models for tissue-engineered bone constructs. Biomaterials. 2004;25:1475-1485.

231 Subach BR, Haid RW, Rodts GE, Kaiser MG. Bone morphogenetic protein in spinal fusion: overview and clinical update. Neurosurg Focus. 2001;10:E3.

232 Carlisle E, Fischgrund JS. Bone morphogenetic proteins for spinal fusion. Spine J. 2005;5:240S-249S.

233 Yong MR, Saifzadeh S, Askin GN, Labrom RD, Hutmacher DW, Adam CJ. Establishment and characterization of an open minithoracotomy surgical approach to an ovine thoracic spine fusion model. Tissue Eng Part C Methods. 2013 Jul 10. [Epub ahead of print].

234 Schantz JT, Lim TC, Ning C, Teoh SH, Tan KC, Wang SC, Hutmacher DW. Cranioplasty after trephination using a novel biodegradable burr hole cover: technical case report. Neurosurgery. 2006;58:ONS-E176; discussion ONS-E176.

235 Ast MP, Nam D, Haas SB. Patient-specific instrumentation for total knee arthroplasty: a review. Orthop Clin North Am. 2012;43:e17e22.

236 Krishnan SP, Dawood A, Richards R, Henckel J, Hart AJ.A review of rapid prototyped surgical guides for patient-specific total knee replacement. J Bone Joint Surg Br. 2012;94:1457-1461.

237 Schweizer, A. New technologies in planning and performance of osteotonics: example cases in hand surgery. Praxis (Bern 1994) 2013;102:579-584

238 Benum P, Aamodt A. Uncemented custom femoral components in 
hip arthroplasty. Acta Orthop. 2010;81:427-435.

239 Eufinger H, Saylor B. Computer-assisted prefabrication of individual craniofacial implants. AORN J. 2001;74:648-654; quiz 655-656, 658-662.

240 Fuster-Torres MA, Albalat-Estela S, Alcañiz-Raya M, PeñarrochaDiago M. CAD/CAM dental systems in implant dentistry: update. Med Oral Patol Oral Cir Bucal. 2009;14:E141-E145.

241 Muirhead-Allwood S, Sandiford NA, Skinner JA, Hua J, Muirhead W, Kabir C, Walker PS. Uncemented computer-assisted designcomputer-assisted manufacture femoral components in revision total hip replacement: a minimum follow-up of ten years. J Bone Joint Surg Br. 2010;92:1370-1375.

242 Muirhead-Allwood SK, Sandiford N, Skinner JA, Hua J, Kabir C, Walker PS. Uncemented custom computer-assisted design and manufacture of hydroxyapatite-coated femoral components: survival at 10 to 17 years. J Bone Joint Surg Br. 2010;92:1079-1084.
243 Brune JC, Hesselbarth U, Seifert P, Nowack D, von Versen R, Smith MD, Seifert D. CT lesion model-based structural allografts: custom fabrication and clinical experience. Transfus Med Hemother. 2012, 39:395-404

244 Lantada AD, Morgado PL. Rapid prototyping for biomedica engineering: current capabilities and challenges. Annu Rev Biomed Eng. 2012;14:73-96.

245 Probst FA, Hutmacher DW, Müller DF, Machens HG, Schantz JT. Calvarial reconstruction by customized bioactive implant. Handchir Mikrochir Plast Chir. 2010;42:369-373.

246 Holzapfel BM, Chhaya MP, Melchels FP, Holzapfel NP, Prodinger PM, von Eisenhart-Rothe R, van Griensven M, Schantz JT, Ruder M, Hutmacher DW. Can bone tissue engineering contribute to therapy concepts after resection of musculoskeletal sarcoma? Sarcoma. 2013;2013:153640. 